\title{
TITLE
}

\section{Reduced light access promotes hypocotyl growth via autophagy-mediated recycling}

Yetkin Çaka Ince ${ }^{1}$, Anne Sophie Fiorucci ${ }^{1}$, Martine Trevisan ${ }^{1}$, Vinicius Costa Galvão ${ }^{1}$, Johanna Krahmer ${ }^{1}$, Leonore Wigger ${ }^{2}$, Sylvain Pradervand ${ }^{2}$, Laeticia Fouillen ${ }^{3}$, Pierre Van Delft ${ }^{3}$, Sebastien Mongrand ${ }^{3}$, Hector Gallart-Ayala ${ }^{4}$, Julijana Ivanisevic ${ }^{4}$ and Christian Fankhauser ${ }^{1}$

${ }^{1}$ Center for Integrative Genomics, Faculty of Biology and Medicine, Génopode Building, University of Lausanne, CH-1015 Lausanne, Switzerland.

${ }^{2}$ Genomic Technologies Facility, Faculty of Biology and Medicine, Génopode Building, University of Lausanne, CH-1015 Lausanne, Switzerland.

${ }^{3}$ Univ. Bordeaux, CNRS, Laboratoire de Biogenèse Membranaire, UMR 5200, F-33140 Villenave d'Ornon, France.

4 Metabolomics Platform, Faculty of Biology and Medicine, Rue du Bugnon 19, University of Lausanne, CH-1005 Lausanne, Switzerland.

\section{HIGHLIGHTS}

- $\quad$ Reduced light and LRFR induce catabolism and anabolism, respectively

- Reduced light promotes autophagy to enhance hypocotyl growth in vegetative shade

- LRFR enhances hypocotyl growth by promoting plasma membrane lipid biosynthesis

- In LRFR, PIFs promote sterol biosynthesis specifically in the hypocotyl 


\section{SUMMARY}

Plant growth ultimately depends on fixed carbon, thus the available light for photosynthesis. Due to canopy light absorption properties, vegetative shade combines reduced light and a low red to far-red ratio (LRFR). In shade-avoiding plants, these two conditions independently promote growth adaptations to enhance light access. However, how these conditions, differing in photosynthetically-available light, similarly promote growth remains unknown. Here, we show that Arabidopsis seedlings adjust metabolism according to light conditions to supply resources for hypocotyl growth enhancement. Transcriptome analyses indicate that reduced light induces starvation responses, suggesting a switch to a catabolic state to promote growth. Accordingly, reduced light promotes autophagy. In contrast, LRFR promotes anabolism including biosynthesis of plasmamembrane sterols downstream of PHYTOCHROME-INTERACTING FACTORs (PIFs) acting in hypocotyls. Furthermore, sterol biosynthesis and autophagy are indispensable for shade-induced hypocotyl growth. We conclude that vegetative shade enhances hypocotyl growth by combining autophagy-mediated recycling and promotion of specific anabolic processes.

KEYWORDS Shade avoidance, Phytochrome Interacting Factor (PIF), sterol biosynthesis, autophagy, plasma membrane, Arabidopsis, hypocotyl, recycling, low blue, low red/far-red, reduced light (PAR) 


\section{INTRODUCTION}

Plants use a portion of electromagnetic spectrum for photosynthesis that is called photosynthetically active radiation (PAR, 400-700 nm) and composed of blue (B, 400-500 $\mathrm{nm})$, green $(\mathrm{G}, 500-600 \mathrm{~nm})$ and red $(\mathrm{R}, 600-700 \mathrm{~nm})$ light (McCree, 1971). Leaves absorb more than $90 \%$ of $\mathrm{B}$ and $\mathrm{R}$ radiation, whereas they transmit and/or reflect a most of the farred light (FR, 700-760 nm) (Liu and van Iersel, 2021). Therefore, plants under vegetative shade receive light combining low $\mathrm{B}$ (LB) and FR enrichment relative to $\mathrm{R}$ light leading to a low R/FR ratio (LRFR) (Casal, 2013). In shade-avoiding plants, LB and LRFR independently trigger a suite of similar adaptive responses including growth of stem-like structures e.g. hypocotyls and petioles to enhance light access (Fiorucci and Fankhauser, 2017, Buti et al., 2020, Wang et al., 2020, Ballare and Pierik, 2017). Plants in dense communities also receive LRFR due to FR reflection from neighboring leaves before actual shading. This is perceived as a neighbor proximity/shade threat signal and triggers similar growth adaptation as vegetative shade prior to a decline in light resources (Casal, 2013, Fiorucci and Fankhauser, 2017). Plant growth depends on fixed carbon (Smith and Stitt, 2007), which depends on PAR including B and R light (Moraes et al., 2019, Liu and van Iersel, 2021). Therefore, how LB and LRFR with contrasting carbon resource availability promote similar growth adaptations remains unclear (Hersch et al., 2014).

While molecular mechanisms underlying hypocotyl growth promotion are relatively well understood in LRFR, they remain unclear in LB (Buti et al., 2020, Wang et al., 2020, Ballare and Pierik, 2017). LRFR inactivates phytochrome B (phyB), leading to derepression of Phytochrome-Interacting Factors (PIFs) transcription factors (TFs) (Buti et al., 2020, Legris et al., 2019, Wang et al., 2020, Fernandez-Milmanda and Ballare, 2021). PIF7, with substantial contributions of PIF4 and PIF5, enhances auxin production in cotyledons through induction of YUCCAs (YUC2, YUC5, YUC8 and YUC9) coding for auxin biosynthesis enzymes (Hornitschek et al., 2012, Kohnen et al., 2016, Li et al., 2012, Muller-Moule et al., 2016, Nito et al., 2015, Nozue et al., 2015). Auxin is rapidly transported to the hypocotyl where it locally induces elongation, presumably through a combined auxin and PIF transcriptional response (Keuskamp et al., 2010, Procko et al., 2014, Oh et al., 2014, Kohnen et al., 2016). Additional hormones, notably brassinosteroids (BR) are also important for LRFR-induced hypocotyl growth (Cifuentes-Esquivel et al., 


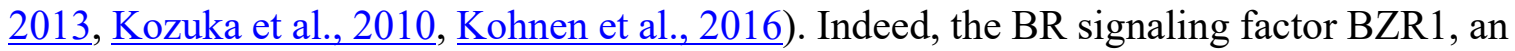
auxin response factor ARF6 and PIF4 collectively regulate target gene expression ( $\underline{\mathrm{Oh}}$ et al., 2014). PIFs are also key TFs for LB-induced hypocotyl elongation, where PIF4 is the primary one with contributions of PIF7 and PIF5 (de Wit et al., 2016, Keller et al., 2011,

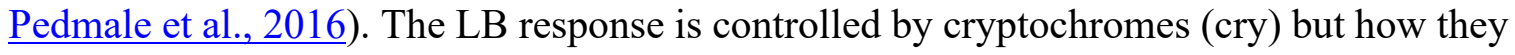
control PIFs remains poorly understood. The cryl-PIF4 interaction represses PIFtranscriptional activity in a B light-dependent manner (Ma et al., 2016, Pedmale et al., 2016). In LB cry2 interacts with PIF4/PIF5 but the functional importance of this complex remains unclear (Ma et al., 2016, Pedmale et al., 2016). Despite auxin and BR being indispensable for hypocotyl elongation in LB, this is not apparent from the transcriptional response, which contrasts with LRFR conditions (de Wit et al., 2016, Keller et al., 2011,

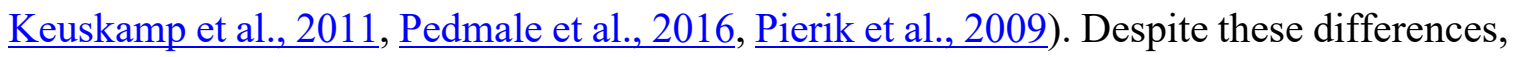
several growth-related pathways (e.g. cell wall organization) are transcriptionally activated in LB and LRFR (Keuskamp et al., 2011, Kohnen et al., 2016, Pedmale et al., 2016). Nevertheless, the lack of spatial resolution, limits our current understanding of LB vs LRFR growth-promoting mechanisms and the role of PIFs in hypocotyls.

Hypocotyl growth occurs by cell elongation where plasma membrane extension is essential

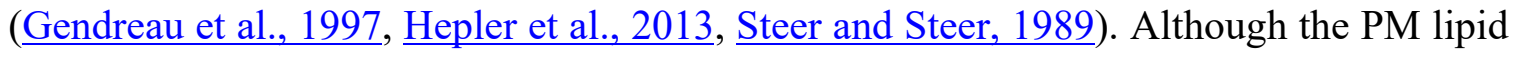
bilayer can transit between tighter or looser packing depending on several parameters, the PM is fairly rigid with a limited expansion and contraction ability (Mamode Cassim et al., 2019). Furthermore, PM curvature is low, also limiting its extension potential (Boutté and Jaillais, 2020). In rapidly elongating plant cells (e.g., pollen tubes and root hair cells), the PM grows with the deposition of new lipid material through the fusion of Golgi-derived vesicles carrying new cell wall material (Hepler et al., 2013, Steer and Steer, 1989). We previously reported that LRFR increases carbon allocation to lipids in $B$. rapa hypocotyls (de Wit et al., 2018). Furthermore, LRFR induces sterol biosynthesis gene expression in hypocotyls (Kohnen et al., 2016). Sterols compose up to $30 \%$ of PM lipids (Mamode Cassim et al., 2019). They regulate PM permeability and fluidity (Mamode Cassim et al., 2019, Valitova et al., 2016). Together with sphingolipids, sterols are enriched in PM lipid microdomains that serve as anchoring platforms for signaling and transport proteins ( $\mathrm{Yu}$ et al., 2020, Gronnier et al., 2019). Their major structural and functional roles at the PM 
suggest an important function of sterols in shade-induced hypocotyl elongation.

Production of new material required for cell elongation ultimately depends on availability of carbon compounds (Verbancic et al., 2018, Smith and Stitt, 2007). LRFR does not decrease carbon fixation in B. rapa seedlings, as PAR remains unchanged (de Wit et al., 2018). However, reducing PAR either by decreasing B, G or R light decreases carbon fixation (Liu and van Iersel, 2021, Moraes et al., 2019). Thus, carbon fixation is expected to decrease in LB, limiting the availability of carbon compounds that are required to promote hypocotyl growth. Carbon starvation triggered by transferring plants into darkness for several days induces autophagy that recycles unessential cytoplasmic materials by vacuolar hydrolases (Chen et al., 2019, Li and Vierstra, 2012, Wang et al., 2018). The fact that LB and LRFR differ in PAR suggests that different mechanisms may be deployed to enable cell elongation in these distinct conditions.

Analyzing light-regulated gene expression in dissected hypocotyls was informative to understand hypocotyl growth regulation during de-etiolation and in LRFR (Kohnen et al., 2016, Sun et al., 2016), but we lack equivalent data for LB. Thus, we performed organspecific gene expression to compare and contrast the mechanisms underlying hypocotyl growth promotion in LB vs LRFR. We show that in LRFR PIFs induce PM sterols biosynthesis in hypocotyls to promote growth, while in LB autophagy is important for hypocotyl growth enhancement. Finally, we provide evidence for the need of combined LRFR-induced anabolic activities and LB-induced autophagy to enable hypocotyl elongation in vegetative shade. 


\section{RESULTS}

\section{LB and LRFR induce distinct transcriptional changes in elongating hypocotyls}

Consistent with previous studies (de Wit et al., 2016, Pedmale et al., 2016), LB and LRFR treatments independently induced hypocotyl elongation in a PIF and YUC dependent manner (Fig. 1A). We hypothesized a convergence of LB and LRFR transcriptome in hypocotyls where both light conditions trigger cell elongation. Thus, we performed transcriptome analyses in dissected cotyledons and hypocotyls of Col-0 (wild type -WT), pif457, and yuc2589 seedlings in white light (WL), LB, and LRFR to characterize the organ-specific LB and LRFR responses and their dependency on PIFs and YUC-mediated auxin biosynthesis (Fig. 1B).

Principle component (PC) analysis showed that biological replicates of each genotype, organ and condition clustered closely (Fig. S1A). In WT hypocotyls, LRFR induced more transcriptome changes than LB; while in cotyledons it was the opposite (Fig. 1C, S1B, Table S1). The number of common up- and downregulated genes were higher in hypocotyls than cotyledons (Fig. 1C, S1B), suggesting a convergence of LB and LRFR transcriptome in elongating hypocotyls. This was confirmed by GO term enrichment analyses for LBspecific, LRFR-specific and LB and LRFR shared upregulated genes (Fig 1D, S1C, Table S2). We highlighted selected terms for each organs and light conditions that we could easily relate to growth regulation (Fig 1D, S1C) (full lists are available in Table S2). LB and LRFR shared upregulated genes in hypocotyls were enriched in terms related to cellular elongation such as "growth", "cell wall organization or biogenesis", "exocytosis", “endocytosis", "cytoskeleton organization", "lipid biosynthetic process" and "response to brassinosteroid" (Fig. 1D). Interestingly, genes specifically upregulated by LB in both organs were enriched in GO terms related to starvation (e.g. "cellular response to sucrose starvation") and catabolic events (e.g. "protein catabolic process", "cellular lipid catabolic process" and "autophagy") (Fig. 1D, S1C). In contrast, LRFR specific genes in hypocotyls were enriched in biosynthetic processes including "ribosome biogenesis", "peptide biosynthetic process", "sterol biosynthetic process", and "cell wall organization and biogenesis" (Fig. 1D). In line with previous reports (Kohnen et al., 2016), LRFR induced many hormone related responses in cotyledons and "response to auxin" in hypocotyls (Fig. 1D, S1C). Altogether, GO term enrichment analyses from light-specific and shared gene 
bioRxiv preprint doi: https://doi.org/10.1101/2021.06.16.448628; this version posted June 17, 2021. The copyright holder for this preprint (which was not certified by peer review) is the author/funder, who has granted bioRxiv a license to display the preprint in perpetuity. It is made available under aCC-BY-NC-ND 4.0 International license.

sets indicate that LB and LRFR transcriptome responses converge in elongating hypocotyls, on the induction of several growth-related mechanisms. However, we observed a striking difference between these treatments with LB upregulating numerous catabolic processes while LRFR inducing many in anabolism.

A

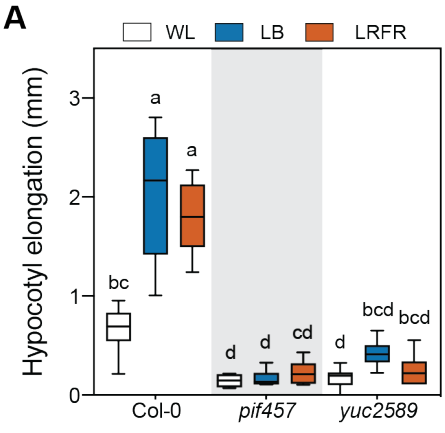

B

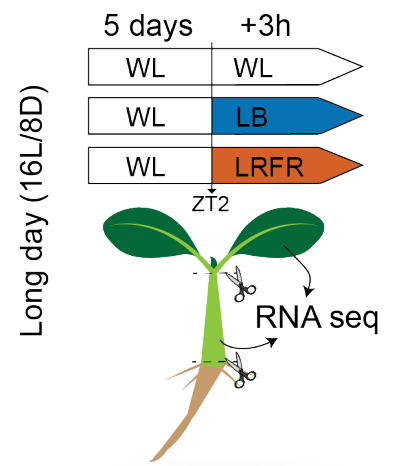

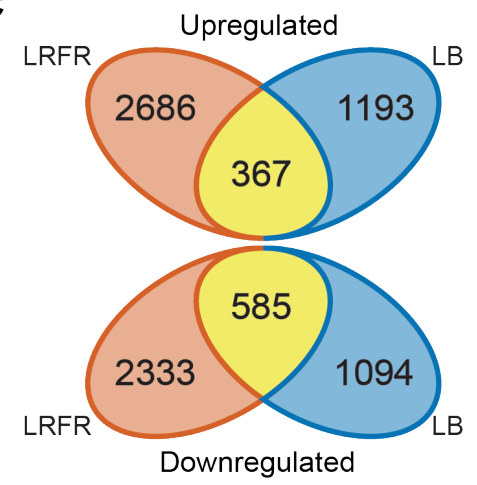

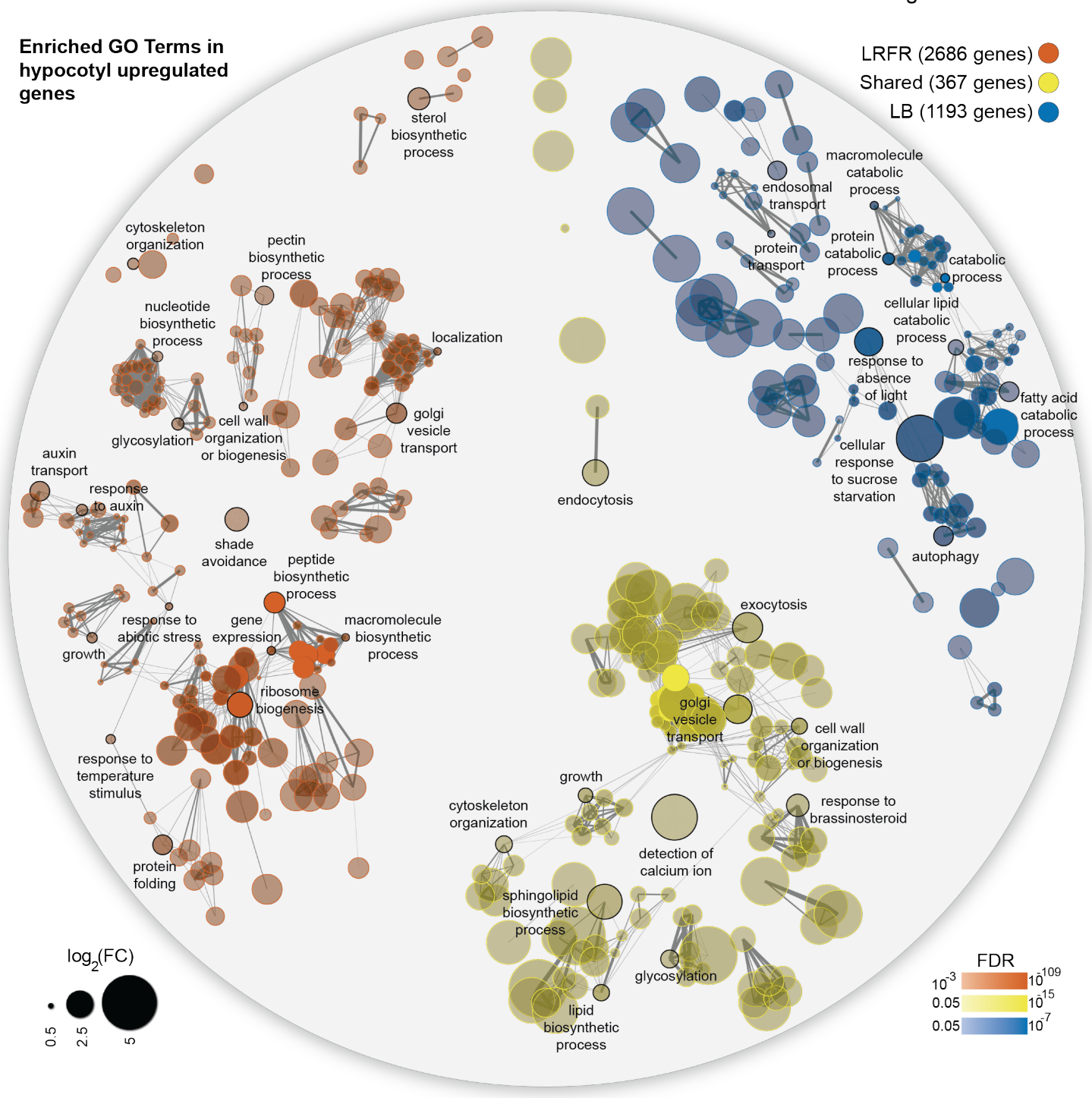


Figure 1. LB and LRFR induce distinct transcriptional changes in elongating hypocotyls.

(A) Hypocotyl elongation of the indicated genotypes. The horizontal bar represents the median; boxes extend from the 25th to the 75th percentile, whiskers extend to show the data range. Different letters indicate significant differences ( $\mathrm{P}<0.05, \mathrm{n}>12$, two-way ANOVA with Tukey's HSD test). (B) Schematic summary of experimental set-up used for transcriptome analysis. (C) Number of up- and downregulated genes in Col0 hypocotyls in the indicated light conditions ( $F D R<0.05$, T-test with $\mathrm{BH}$ correction). (D) GO term enrichment analysis in Col-0 hypocotyl upregulated gene lists. Each node indicates a significantly enriched GO term (FDR $<0.05)$. Two terms (nodes) are connected if they share $20 \%$ or more genes. The line thickness increases with the increasing number of shared genes between two terms. Only selected GO terms (black outlines) are annotated. The full list of enriched GO terms is in Table S2, the interactive version of (D) is available here. See also Figure S1.

\section{Most LRFR-induced genes in hypocotyls require both PIFs and YUCs}

In accordance with the established role of PIFs and YUCs for LRFR responses (Hornitschek et al., 2012, Kohnen et al., 2016, Li et al., 2012, Muller-Moule et al., 2016, Nito et al., 2015, Nozue et al., 2015, Lorrain et al., 2008), gene expression in pif457 and yuc2589 was largely unresponsive to LRFR (Fig. S1A). PCA showed that hypocotyls of LRFR-treated pif457 and yuc2589 grouped with WL samples but yuc2589 cotyledons grouped closer to WT LRFR samples (Fig. S1A). We also evaluated the individual roles of PIFs and YUCCAs by analyzing the interactions between genotypes and light treatments. These comparisons revealed four groups among LRFR-upregulated genes: PIF and YUC dependent, only PIF dependent, only YUC dependent, and dependent on neither (Fig. 2A, S2A, Table S3). In hypocotyls, most LRFR-induced genes required both PIFs and YUCs, whereas the largest fraction depended on only PIFs in cotyledons (Fig. 2A, S2A). The extent of LRFR regulation was reduced in pif457 and yuc2589 also in PIFand/or YUC-independent categories (Fig. 2B, S2B), indicating that our classification underestimates the importance of PIFs and YUCs. Thus, these data demonstrate that LRFR-regulated gene expression largely depends on PIF4, PIF5 and PIF7. Moreover, while in cotyledons the regulation of many genes depends on PIFs alone, in the hypocotyl their regulation depends on PIFs and YUCs.

We performed GO enrichment analyses to characterize the processes depending on PIFs and YUCs (Table S3). In hypocotyls, terms such as "cell wall organization and biogenesis", "response to brassinosteroids", "response to auxin" and "auxin transport" heavily 
depended on PIFs and YUCs with a particularly strong dependency for terms related to lipid biosynthesis (Fig. 2C). In the major light-sensing organ (cotyledons), terms related to the biosynthesis of multiple hormones required PIFs but not YUCs (Fig. S2C). In contrast, genes induced in the rapidly growing hypocotyl required both PIFs and YUCs and were related to hormone responses, cell wall organization and lipid biosynthesis. Given that LRFR YUC-dependent auxin production mostly occurs in cotyledons, this indicates that in hypocotyls LRFR gene induction largely depends on auxin transported from the cotyledons with a potential local action of PIFs.

A

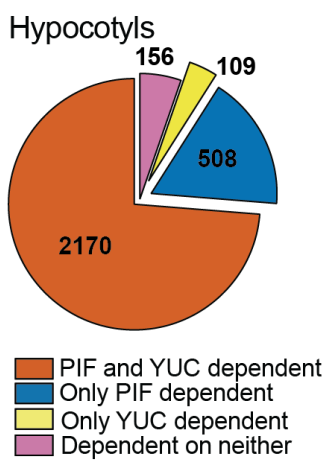

C

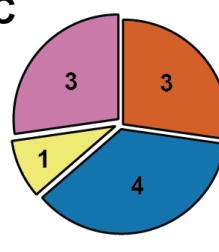

shade avoidance

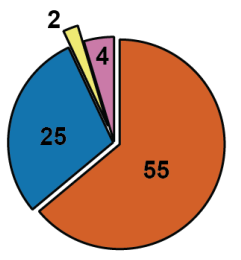

response to auxin
B

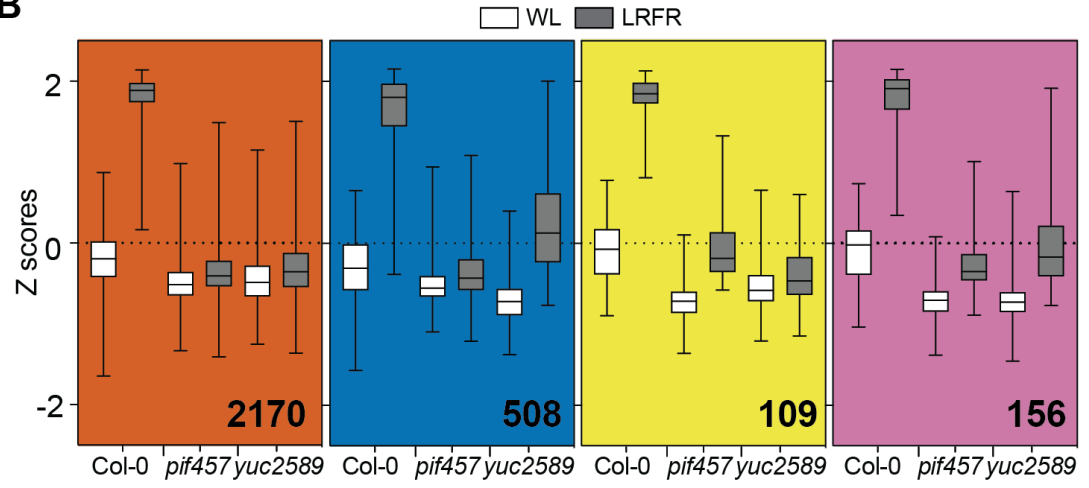

Figure 2. Most LRFR-induced genes in hypocotyls require both PIFs and YUCs.

(A) The distribution of hypocotyl-induced genes in LRFR according to the dependence on PIFs and YUCs using the comparison of Col-0, pif457 and yuc2589 transcriptomes (FDR $<0.05$, F-test with post-hoc test).

(B) Distributions of Z- scores computed from replicates averages for categories shown in (A). The horizontal bar represents the median; boxes extend from the 25th to the 75th percentile, whiskers extend to show the data range. (C) The distribution of hypocotyl-induced genes according to the dependence on PIFs and YUCs in each of the selected significantly enriched GO terms. Numbers indicate significantly regulated genes in 
the given categories and/or GO terms. The full list of misregulated genes and enriched GO terms are given in Table S3. See also Figure S2.

\section{The majority of LB-induced genes do not depend on PIFs or YUCs.}

Based on PCA, pif457 and yuc2589 displayed a robust transcriptional response to LB, contrasting with LRFR (particularly in hypocotyls) and the phenotypes of these mutants (Fig. S1A, 1A). Nevertheless, part of LB upregulated genes including some related to protein catabolism and secretion/organelle transport processes depended on PIFs and/or YUCs (Fig. 3A, 3B, S3A, list of genes and GO term analysis are given in Table S4). However, the biggest fraction of LB-induced genes did not depend on PIFs and/or YUCs (Fig. 3A, 3B, S3A). One possibility is that LB-induced hypocotyl elongation requires optimal expression of genes in WL (baseline conditions), where we found hundreds with lower expression in pif457 and/or yuc2589 compared to WT (Fig. 3C, Table S5). Similarly to LRFR, most WL-misregulated genes in hypocotyls required both PIFs and YUCs, whereas in cotyledons more required PIFs only (Fig. 3C, S3B). Although LB did not strongly induce these genes in the WT, the expression levels in the mutants were also lower in LB (Fig. 3D). Many GO terms related to growth, hormones and cell wall as well as "response to blue light" and "response to starvation" were enriched in the PIF- and YUCdependent genes in hypocotyls (Fig. S3C, Table S5). Therefore, we conclude that in contrast to LRFR, LB-gene induction was less dependent on PIFs and YUCs.

Finally, we compared each set of PIF-dependent genes in WL, LB, and LRFR with PIF4 putative targets (Pedmale et al., 2016) (Table S6). PIF-dependent genes in WL and LRFR (Fig. 2, 3C, S3B) were significantly enriched in PIF4 targets for both organs (Fig. 3E, S3D). One exception was PIF and YUC dependent genes in LRFR in hypocotyls, which may indicate that these genes are induced by auxin produced downstream of PIFs (Fig. 3E). Similarly, for both organs, promoter motif enrichment analysis showed that G-box and PBE-box elements are overrepresented PIF-dependent genes in WL and LRFR but not in LB (Fig 3E, S3D, Table S6). These results suggest that PIFs directly regulate a number of genes in WL conditions, which may contribute to the impaired LB hypocotyl elongation of pif457 mutants. 


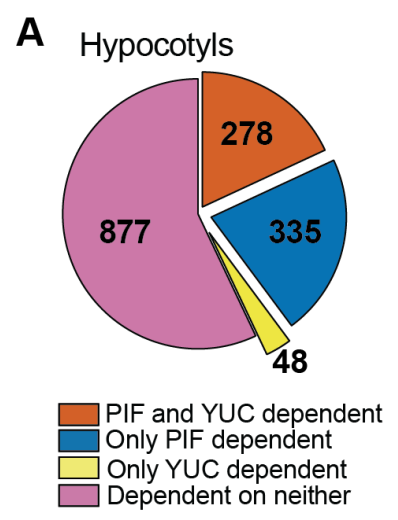

C

Misregulated genes in WL

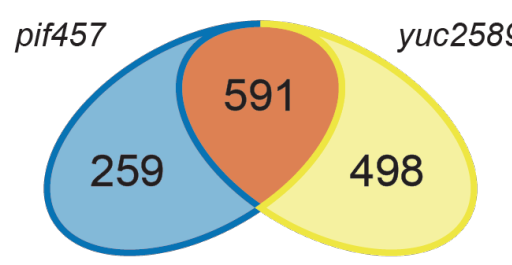

Hypocotyls
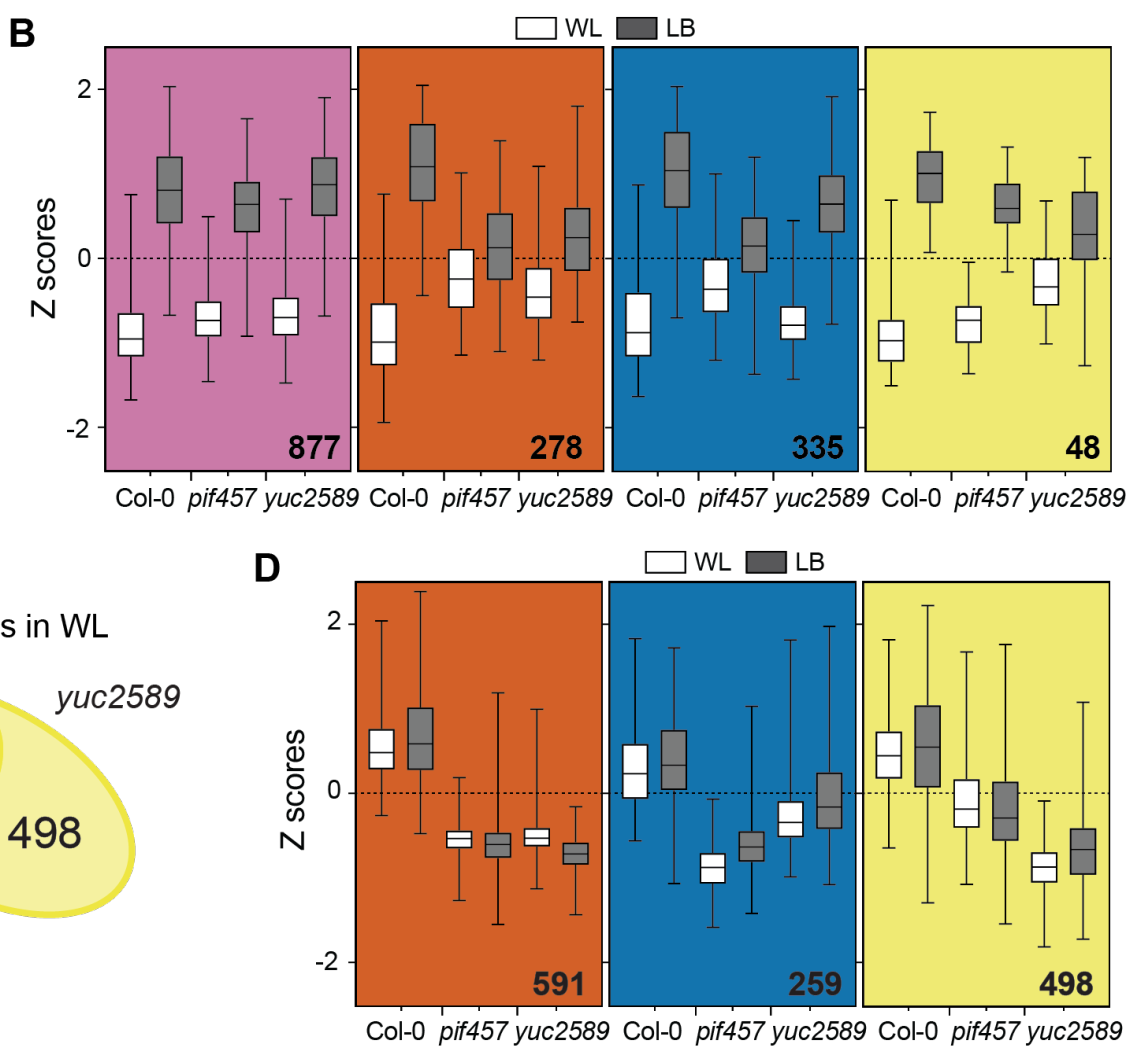

E

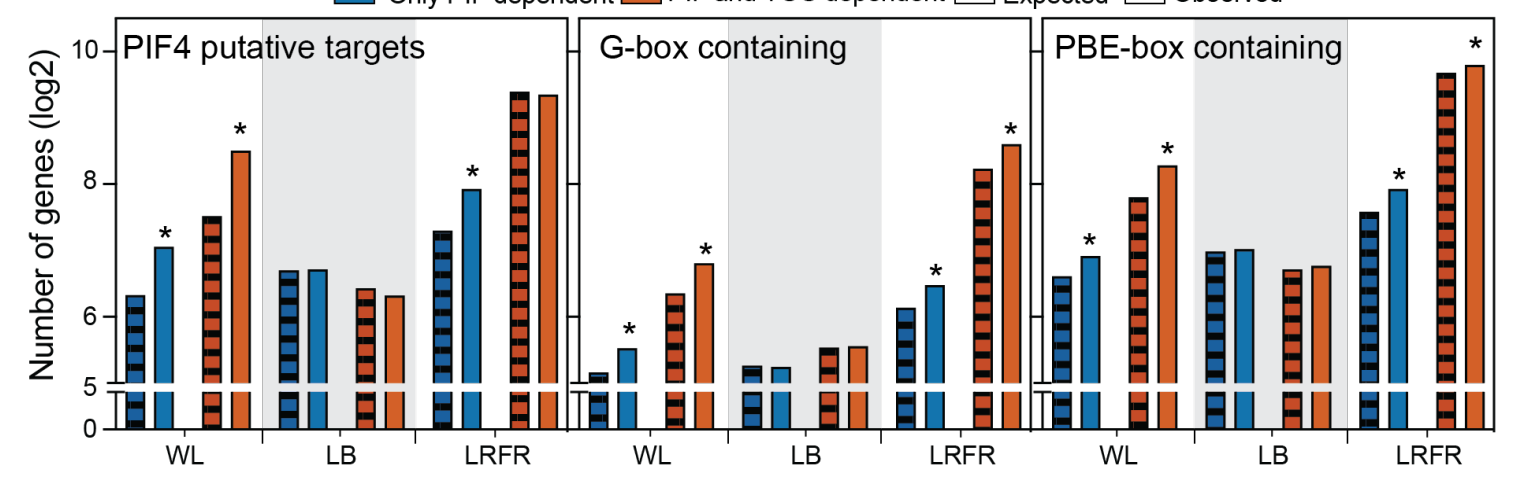

Figure 3. PIFs \& YUCs are required for basal expression of many growth- and hormone- associated genes in hypocotyls of WL-grown seedlings.

(A) The distribution of hypocotyl-induced genes in LB according to the dependence on PIFs and YUCs using the comparison of Col-0, pif457 and yuc2589 transcriptomes (FDR $<0.05$, F-test with post-hoc test). (B) Distributions of Z- scores computed from replicates averages for categories shown in (A). (C) Number of misregulated genes in pif457 and yuc2589 hypocotyls compared to Col-0 in WL (FDR $<0.05$, T-test with BH correction). (D) Distributions of Z- scores computed from replicates averages for genes that are grouped as in (C). (E) Comparison of PIF dependent genes in hypocotyls with PIF4 putative targets (as listed in (Pedmale et al., 2016)), promoters (1 kb upstream) containing G-box (CACGTG) or PBE-box (CATGTG). Asterisks $\left.{ }^{*}\right)$ indicate the statistically significant overrepresentation compared to expected $(\mathrm{P}<0.05$, Binomial distribution). (B, D) The horizontal bar represents the median; boxes extend from the 25th to the 75th 
percentile, whiskers extend to show the data range. Numbers indicate significantly regulated genes in the given categories and/or GO terms. The full list of misregulated genes, enriched GO terms, and enriched motifs are given in Table S4, S5, and S6. See also Figure S3.

\section{In LRFR PIFs induce SMT2 expression in the hypocotyl to promote growth}

We confirmed that in hypocotyls LRFR induces numerous genes in diverse anabolic processes (Fig. 1D) (Kohnen et al., 2016), predominantly downstream of PIFs and YUCs (Fig. 2C, Table S3). The dependency on PIFs could be direct or indirect as they induce YUC-mediated auxin production in cotyledons (Hornitschek et al., 2012, Kohnen et al., 2016, Li et al., 2012, Muller-Moule et al., 2016, Nito et al., 2015, Nozue et al., 2015). Previously, we reported that more cotyledon-fixed carbon was allocated into the lipid fraction of elongating hypocotyl in LRFR in B. rapa (de Wit et al., 2018). Lipid biosynthesis, that is required for membrane expansion in rapidly elongating cells (Hepler et al., 2013, Steer and Steer, 1989), was a prominent example of anabolic processes regulated by PIFs in LRFR (Fig. 2C). We focused on sterols because of a global upregulation of the pathway where many genes may be direct PIF targets (Fig. 1D, 2C, S4A) (Chung et al., 2020, Pedmale et al., 2016). Sterols are indispensable constituents of PM and precursors of BR growth hormones and several biosynthesis mutants are either embryo lethal or show major growth defects (Valitova et al., 2016). C-24 sterol methyltransferases (SMT) coded by two paralogs SMT2 and SMT3 synthesize the predominant PM sterol, sitosterol (Fig. 4A) (Carland et al., 2010, Carland, 2002, Hase et al., 2005, Mamode Cassim et al., 2019, Valitova et al., 2016). Sitosterol levels decrease dramatically in smt2 and marginally in smt3 mutants but these mutants still contain high levels of other sterols (e.g. campesterol) and BR and they do not have serious growth defects despite a decrease in the major PM sterol (Carland et al., 2010, Carland, 2002, Hase et al., 2005). This enabled us to conduct physiological and molecular experiments using these mutants.

SMT2 and SMT3 expression were induced only by LRFR selectively in the hypocotyls in a PIF and YUC dependent manner (Fig. 4B). Furthermore, LRFR led to enhanced PIF4HA binding at the promoter regions of SMT2 and SMT3 (Fig. 4C) in PIF4p::PIF4-HA (pif4-101) seedlings (Zhang et al., 2017). We also detected a significant PIF7-HA enrichment on the SMT3 but not the SMT2 promoter (Fig. S4B) in PIF7p::PIF7-HA (pif72) seedlings (Galvao et al., 2019). PIF7-HA binding to SMT3 and HFR1, the latter being 
used as a positive control, was also much lower than PIF4-HA binding (Fig. 4C, S4B). Taken together, our data demonstrate that PIFs induce SMT2 and SMT3 expression specifically in hypocotyls by directly binding to their promoter regions in LRFR.

A

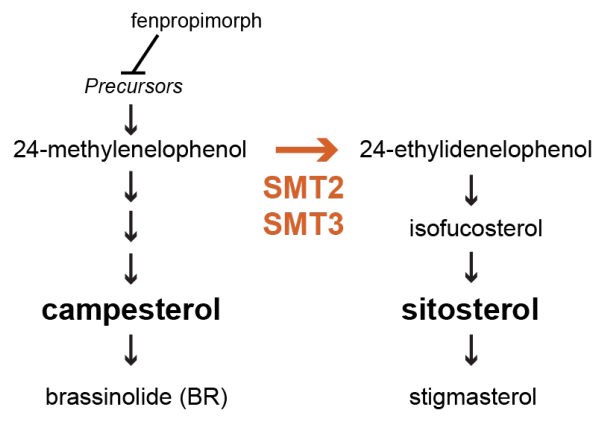

B

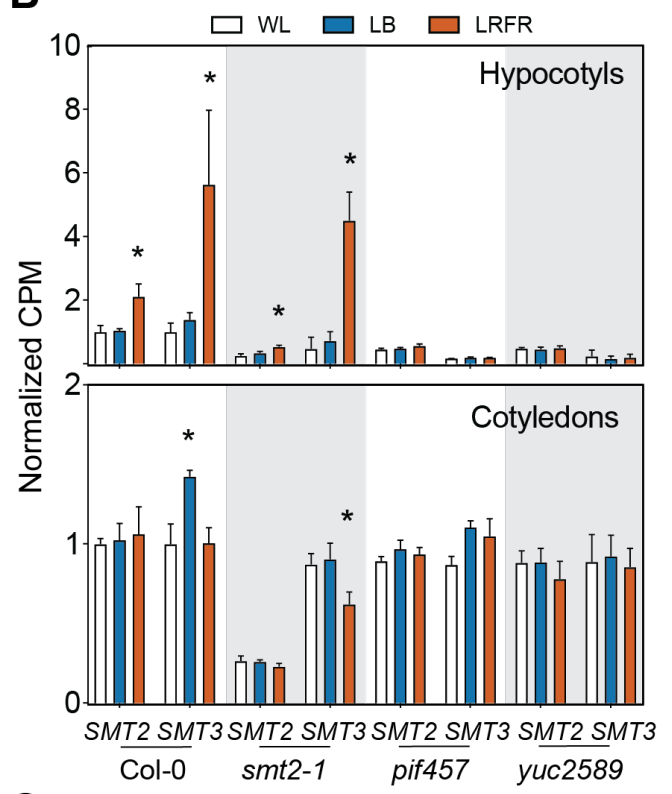

C

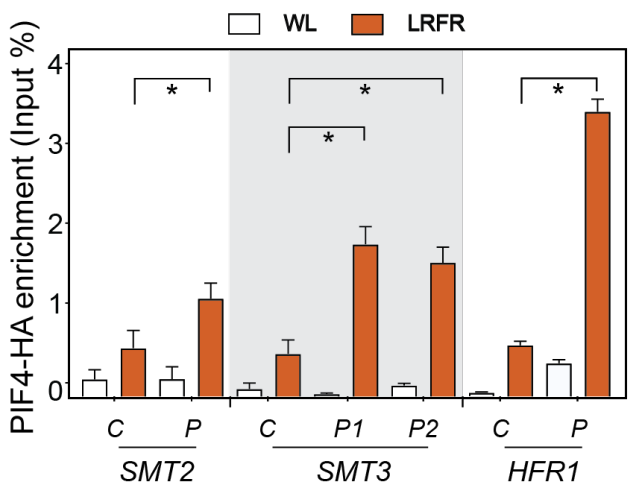

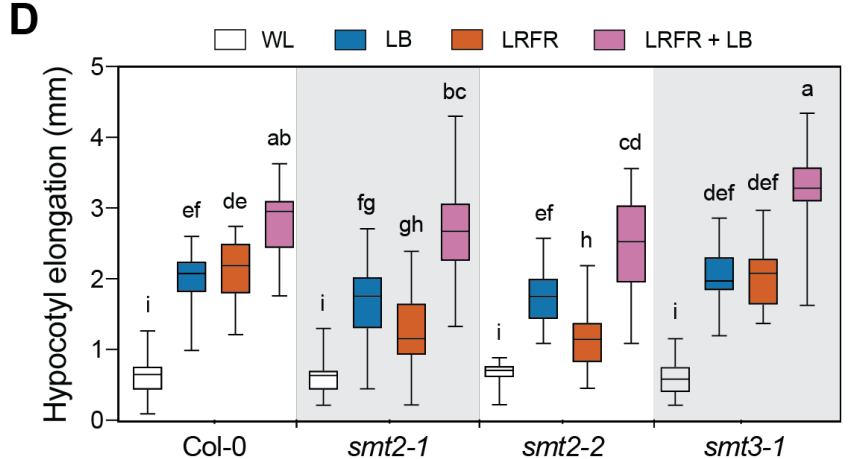

E

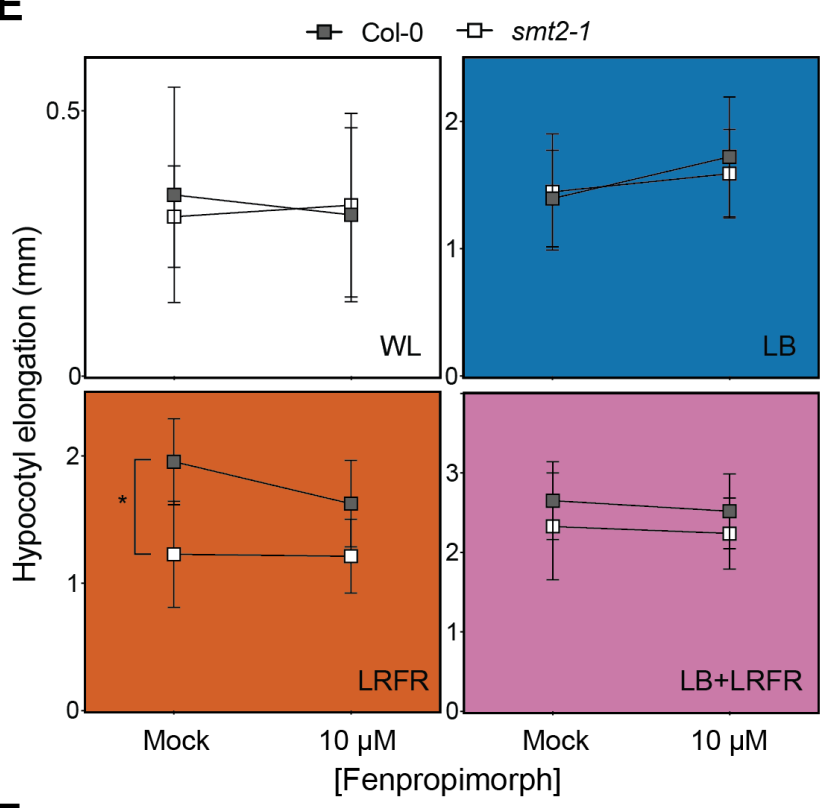

$\mathbf{F}$

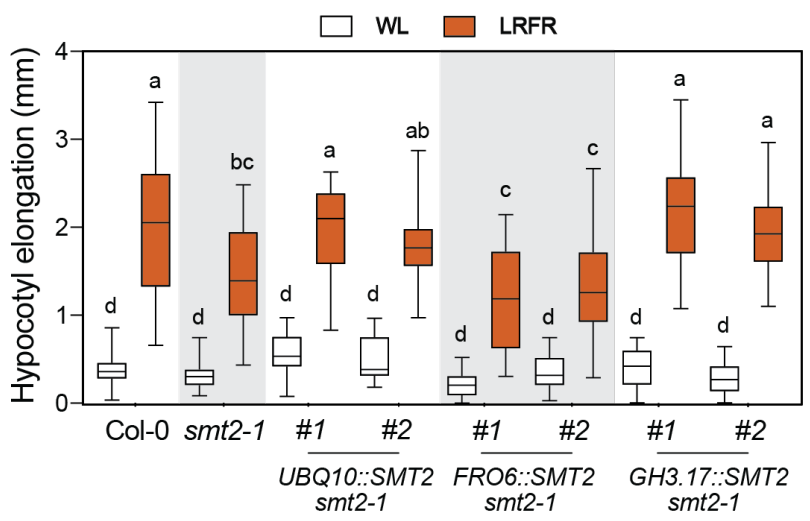

Figure 4. SMT2 is required locally for LRFR-induced hypocotyl elongation.

(A) A simplified representation of sterol biosynthesis pathway in Arabidopsis (Carland et al., 2010). (B) 
Normalized CPM (counts per million, normalized to Col-0 average in WL) of SMT2 and SMT3 in the indicated genotypes and conditions (data from RNA-seq). (C) PIF4-HA binding to the promoter of the indicated genes. PIF4-HA enrichment is quantified by qPCR and presented as IP/Input ( $n=3$, technical). Control - C, Peak - P. (D, E, F) Hypocotyl elongation of the indicated genotypes. (D, F) The horizontal bar represents the median; boxes extend from the 25th to the 75th percentile, whiskers extend to show the data range. (B, C, E) Data are means \pm SD. Different letters (D, F, two-way ANOVA with Tukey's HSD test) and asterisks $\left({ }^{*}\right)(\mathrm{B}, \mathrm{C}, \mathrm{T}$-test) $(\mathrm{E}$, two-way ANOVA) indicate significant difference $(\mathrm{P}<0.05)$ compared to $\mathrm{WL}$ (B) or control (C), and between genotypes in given light condition (E). See also Figure S4.

Using smt2 and smt3 mutants (Carland et al., 2010, Carland, 2002, Hase et al., 2005), we tested the requirement of SMT2 and SMT3 for LRFR-induced hypocotyl elongation. Hypocotyl elongation was significantly reduced in two independent smt2 alleles and $s m t 2 s m t 3$ double mutant, whereas the response to LRFR was unaffected in smt3 (Fig. 4D, S4C). Similarly, when applied simultaneously with light treatments, fenpropimorph, that

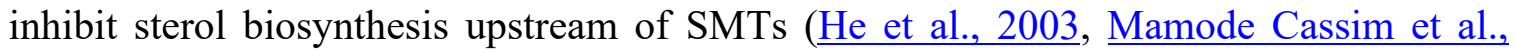
2019), significantly reduced the hypocotyl elongation in LRFR (Fig. 4A, 4E). Furthermore, increased drug concentration resulted in a significantly steeper reduction in hypocotyl elongation of WT compared to smt2-1 in LRFR (Fig. S4D). Importantly, the hypocotyl elongation of smt2 and smt3 mutants was as in the WT in WL and LB (Fig. 4D). These phenotypes highlight the importance of sterol production during LRFR treatment, in correlation with the expression data (Fig 4B, 4D). Remarkably, LB+LRFR combination mimicking vegetative shade rescued the reduced hypocotyl elongation of smt2-1 in LRFR (Fig. 4D). Similarly, inhibition of sterol biosynthesis simultaneously with LB and LB+LRFR did not reduce the hypocotyl elongation (Fig. 4E). This result contrasts with LB and LB+LRFR hypocotyl phenotype of $s m t 2 s m t 3$ that was completely impaired in sitosterol biosynthesis even before the light treatments (Fig. S4C). Collectively our results suggest that SMT2-dependent induction of sitosterol production is particularly important for LRFR-induced hypocotyl elongation.

To determine whether SMT2 is required locally for LRFR-induced hypocotyl growth, we phenotyped smt2-1 complemented with SMT2 coding sequence with promoters specific to cotyledon (FRO6) (Feng et al., 2006) or hypocotyl (GH3.17) (Zheng et al., 2016), in comparison to a ubiquitous (UBQ10) control (Fig. S4E). UBQ10 and GH3.17 driven SMT2 
rescued the smt2-1 phenotype in LRFR in two independent insertion lines for each construct, whereas FRO6 did not (Fig. 4F). Taken together our data indicate that PIFregulated SMT2 expression in hypocotyls is required for LRFR-induced hypocotyl elongation.

\section{Auxin biosynthesis, response and transport are normal in smt2-1 in LRFR}

A

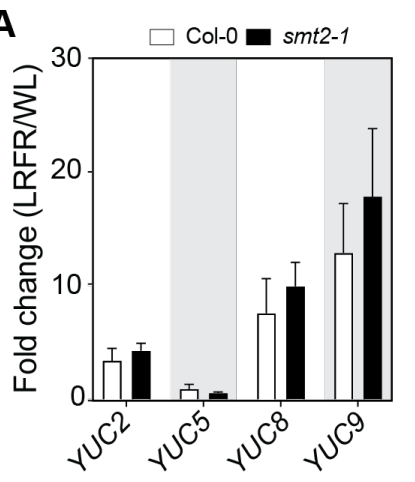

B

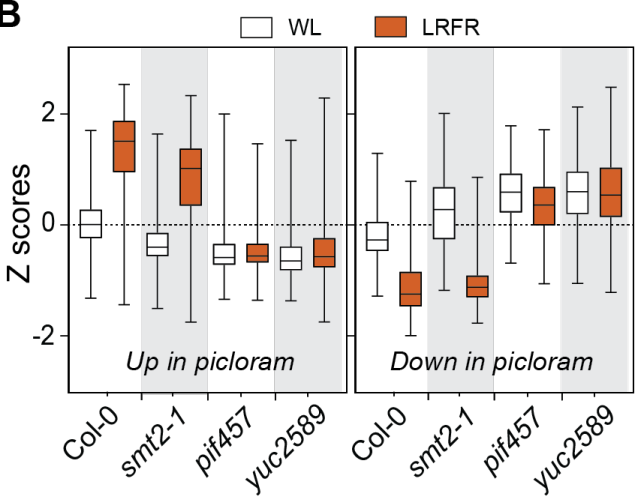

C

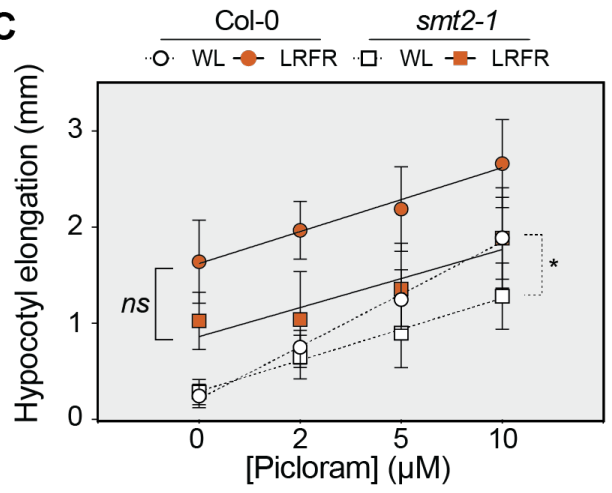

D

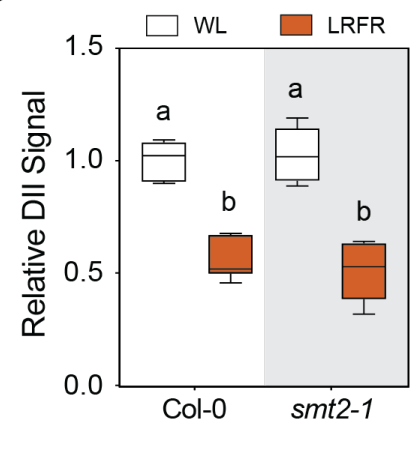

E
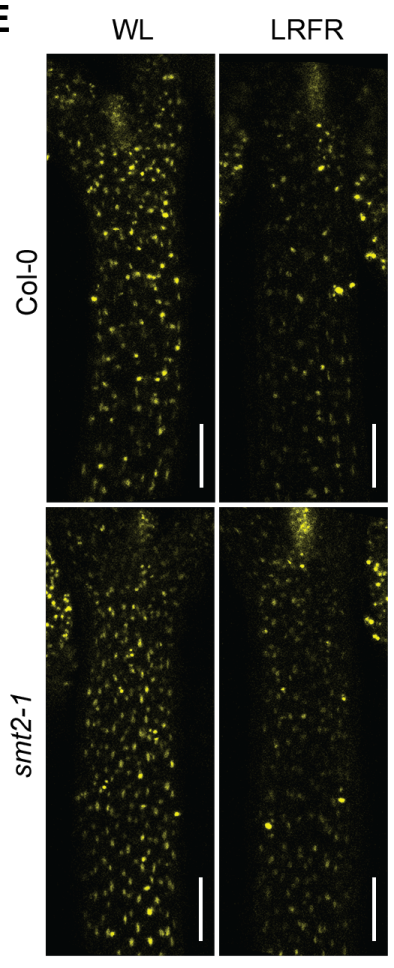

Figure 5. Auxin biosynthesis, response and transport are normal in smt2-1 in LRFR.

(A) LRFR-induction of auxin biosynthetic genes in the indicated genotypes (data from RNA-seq). (B) Distributions of Z- scores computed from replicates averages for synthetic auxin picloram up- and downregulated genes in hypocotyls of the indicated genotypes (as listed in (Chapman et al., 2012). (C) Hypocotyl elongation of indicated genotypes with the indicated doses of picloram $(n>12)$. (D, E) Quantification (D) and the representative images (E) of the DII-VENUS signal intensity (normalized to mean value of Col-0 in WL) in hypocotyls of the indicated genotypes either kept at WL or transferred to LRFR for $1 \mathrm{~h}(\mathrm{n}>6$ ). White bars equal to $100 \mu \mathrm{m}$. (A, C) Data are means \pm SD. (B, D) The horizontal bar represents the median; boxes extend from the 25 th to the 75 th percentile, whiskers extend to show the data range. Different letters (D, two-way ANOVA with Tukey's HSD test) and asterisks (*) (C, two-way ANOVA) indicate significant difference $(\mathrm{P}<0.05)$ between genotypes in given light condition $(\mathrm{C})$ and compared to WL $(\mathrm{D})$. The full gene list of LRFR-picloram transcriptome comparison is given in Table S8. See also Figure S5. 
One characteristic phenotype of the smt 2 and $s m t 2 s m t 3$ mutants is an impaired cotyledon vasculature pattern (cvp) (Fig. S5A) (Carland et al., 2010, Carland, 2002, Hase et al., 2005). Auxin transport from cotyledons to hypocotyls is required for LRFR-induced elongation (Keuskamp et al., 2010, Keuskamp et al., 2011, Procko et al., 2014). Thus, we determined hypocotyl growth of other severe cvp mutants, cvp2 and cvp2cvll (Fig. S5A) that do not interfere with sterol biosynthesis (Carland and Nelson, 2009). Interestingly, both cvp mutants displayed a normal hypocotyl elongation in LRFR (Fig. S5B), suggesting that the cotyledon vasculature problems of smt2 and smt $2 s m t 3$ do not explain their hypocotyl elongation defect. Moreover, we directly analyzed auxin response in smt2-1. PCA and statistical analyses indicated that the transcriptome of smt2-1 is similar to Col-0 in LB and LRFR in both organs (Fig S5C, S5D, Table S7). Transcriptional activation of the major genes coding for auxin biosynthesis in LRFR was also similar in Col-0 and smt2-1 (Fig. 5A). Furthermore, comparison of our LRFR transcriptome and $2 \mathrm{~h}$ picloram (synthetic auxin)-regulated genes in hypocotyls (Chapman et al., 2012) showed a high correlation between these treatments for Col-0 and smt2-1 (Fig. 5B, Table S8), but not in pif457 and yuc2589 which are impaired in auxin biosynthesis in LRFR (de Wit et al., 2015, Kohnen et al., 2016, Nozue et al., 2015). The WT and smt2-1 hypocotyls elongated similarly in LRFR with increasing doses of picloram (Fig. 5C), indicating a similar auxin response. Finally, DII-VENUS signal, a reporter for determining auxin levels (Brunoud et al., 2012), similarly decreased in hypocotyls of LRFR-treated seedlings for both genotypes, indicating increased auxin levels (Fig. 5D, 5E). All together, these results indicate that it is unlikely that the smt2-1 hypocotyl phenotype in LRFR results from altered auxin biosynthesis, transport or response.

\section{LRFR selectively promotes accumulation of PM lipids}

We next analyzed the total lipid content globally in LRFR using untargeted lipidomics (Aldana et al., 2020) in B. rapa hypocotyls where LRFR enhances allocation of newly fixed carbon to the lipids and induces elongation similarly to Arabidopsis (de Wit et al., 2018). The percentage of major PM lipids (glycerolphospholipids - GPL) increased whereas the storage lipids (triacylglycerols - TAG) and the major constituents of thylakoid membranes (glycosyldiracylglycerols - GDG) (Mamode Cassim et al., 2019) decreased significantly in 
LRFR in the total lipid pool (Fig. 6A). We also detected a similar adjustment of lipid profile in Arabidopsis hypocotyls. We used BODIPYTM 493/503 dye that stains neutral lipids (Gocze and Freeman, 1994) to detect the level of lipid droplets (LD) that contains mainly TAG (Graham, 2008). Fluorescence intensity of LDs decreased significantly after 30h of LRFR treatment in Arabidopsis hypocotyls (Fig 6B). Furthermore, our transcriptome data showed that the "thylakoid membrane organization" GO term is enriched in the hypocotyl downregulated genes in LRFR (Table S3). In line with this data and previous reports on tomato stems (Cagnola et al., 2012), the fluorescence intensity of chloroplasts decreased in Arabidopsis hypocotyls in LRFR (Fig 6C). We conclude that LRFR promotes the accumulation of PM lipids in B. rapa hypocotyls whereas storage and chloroplast lipids decrease in the hypocotyls of both B. rapa and Arabidopsis.

A

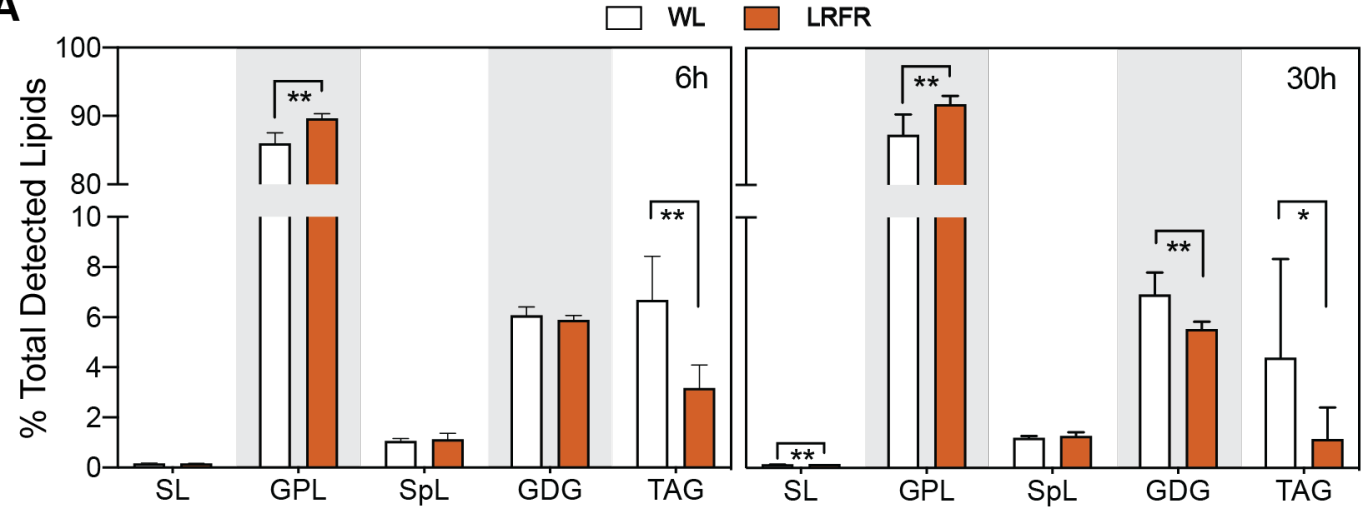

B

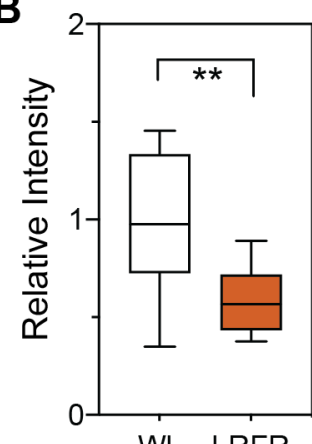

WL LRFR

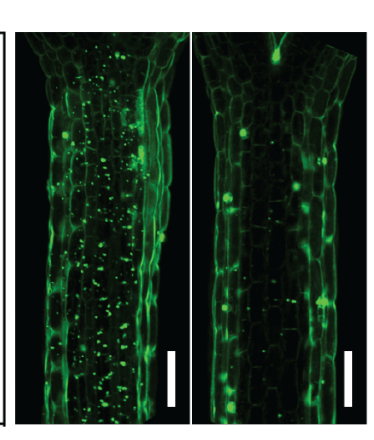

WL

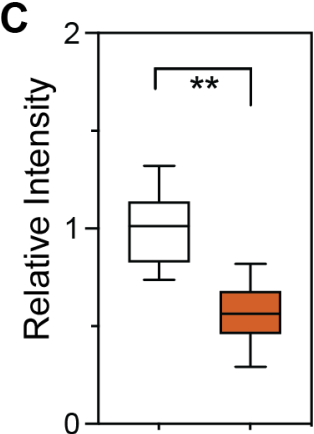

WL LRFR

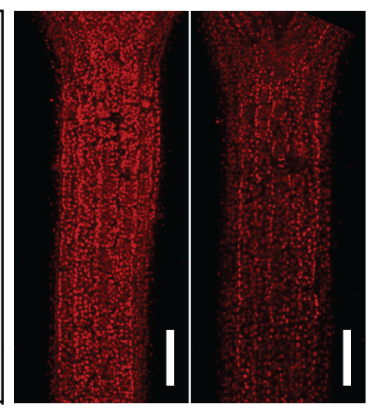

WL

LRFR

Figure 6. LRFR selectively promotes accumulation of PM lipids.

(A) Lipid class abundance at the indicated time points is represented as percentage of total detected lipids in B. rapa hypocotyls ( $\mathrm{n}=5$, biological replicates). Sterol lipids - SL, Sphingolipids -SpL, Glycerophospholipids - GPL, Glycosyldiracylglycerols - GDG, Triacylglycerols - TAG. Data are means \pm SD. (B, C) Quantification (left) and representative images (right) of (B) LDs using BODIPYTM 493/503 and (C) chloroplasts in Col-0 hypocotyls either kept at WL or transferred to LRFR for 30h ( $\mathrm{n}>6$ ). Data is normalized to WL average. White bars equals to $100 \mu \mathrm{m}$. (B, C) The horizontal bar represents the median; boxes extend 
from the 25 th to the 75 th percentile, whiskers extend to show the data range. (A, B, C) Asterisks indicate $\mathrm{P}$ values $(*<0.1, * *<0.05, \mathrm{n} \geq 5$, T-test). The full list of detected lipid species is given in Table S9. See also Figure S6.

Although we focused on SMT2 and SMT3, the expression of many other sterol biosynthesis genes were induced in LRFR in Arabidopsis hypocotyls (Fig. S4A) (Kohnen et al., 2016). This suggests that LRFR induces a general increase in sterols required for elongating PM. Thus, we determined the sterol composition in B. rapa hypocotyls where LRFR-expression profiles of BrSMTs were similar to their orthologs in Arabidopsis (Fig. S6A, BrIAA29 being a control (Procko et al., 2014). Campesterol and sitosterol, the two major sterols in the PM (Valitova et al., 2016), did not change in LRFR during the timeframe of our experiments (Fig. S6B). Yet, the percentage of ergosta-5,7-dienol, a precursor for BRs downstream of campesterol, decreased after $3 \mathrm{~h}$ of LRFR (Fig. S6B). This is in line with the report showing a decrease in another BR precursor level in LRFR (Bou-Torrent et al., 2014). These results suggest that LRFR induces a total increase in sterols rather than a major change in their composition. Taken together, our data suggest that the transcriptional upregulation of sterols and other PM lipids contribute to the buildup of PM in elongating hypocotyl cells.

\section{LB induces autophagy}

In our LB treatment PAR was reduced to $66 \%$ of WL levels while it remained as in WL in LRFR (Fig. S7A). Such a decrease in PAR results in around $50 \%$ reduction in the net $\mathrm{CO}_{2}$ assimilation, regardless of the light color used for illumination $(B, G, R$, or their various combinations) (Liu and van Iersel, 2021). However, carbon fixation remained unchanged in B. rapa seedlings in LRFR (de Wit et al., 2018). In line with these observations, "carbon fixation" GO term is enriched only in LB downregulated genes, while terms related to carbon starvation responses are enriched in LB-induced genes (Fig. 1D, S7B, Table S3, S4). These data suggests that reduced light access induces a switch to a catabolic state to promote growth due to limited carbon availability. Accordingly, we observed the selective enrichment of catabolism terms and "Autophagy" in LB-induced genes (Fig. 1D, 7A). Since ATG8 is found in autophagosomal membranes (Yoshimoto et al., 2004), we used a ubiquitously expressed $m$ Cherry-ATG8e line ( $\underline{\mathrm{Hu} \text { et al., 2020) }}$ to monitor autophagic 
activity in our conditions. The number of autophagic bodies increased in LB-treated cotyledons when a vacuolar-type v-ATPase inhibitor, concanamycin-A (ConA) was present (Fig. 7B, S7C). We did not detect any autophagic bodies in atg5-1, an autophagy deficient mutant even in LB (Stephani et al., 2020, Thompson et al., 2005) (Fig. 7B). These results indicate that LB promotes autophagic flux. Further autophagic flux measurements in LB using 35S::GFP-ATG8a (Thompson et al., 2005) demonstrated that free GFP intensity increased in LB with or without ConA, whereas the full length GFP-ATG8a decreased only in the absence of ConA (Fig. 7C, 7D). As a control, we showed that GFP band intensity remains the same in $35 S:: G F P$ line in WL and LB (Fig. S7D). Altogether, these data indicate that LB promotes transcriptional and post-transcriptional induction of autophagy and the vacuolar degradation of autophagic bodies in Arabidopsis seedlings.

We next determined whether autophagy is required for LB-induced hypocotyl elongation using the autophagy mutant $\operatorname{atg} 7-2$ (Hofius et al., 2009) (Fig. S7E). atg7-2 hypocotyls elongated less in all tested light conditions except WL, with a more pronounced reduction in LB than LRFR (Fig. 7E). Remarkably, the atg7 phenotype was complementary to smt21, which had a stronger phenotype in LRFR than LB (Fig. 7E). Moreover, LB+LRFR combination significantly enhanced hypocotyl elongation in both mutants suggesting a degree of compensation between anabolic and catabolic processes mainly promoted by LRFR and LB respectively (Fig. 7E). Supporting this idea, the smt2atg7 hypocotyls did not elongate in either LB or LRFR (Fig. 7E). Importantly, the smt2atg7 elongation was also very modest in LB+LRFR that induces autophagy similarly to LB (Fig. 7E, 7F, S7F). Thus, we conclude that autophagy is particularly important to promote hypocotyl elongation in LB when PAR decreases and in vegetative shade that combines LB and LRFR. Our study indicates that during the neighbor threat response LRFR-induced anabolic processes (e.g. sterol biosynthesis) fuel hypocotyl elongation, while under vegetative shade a combination of autophagy-mediated recycling and anabolic processes enable hypocotyl growth. 


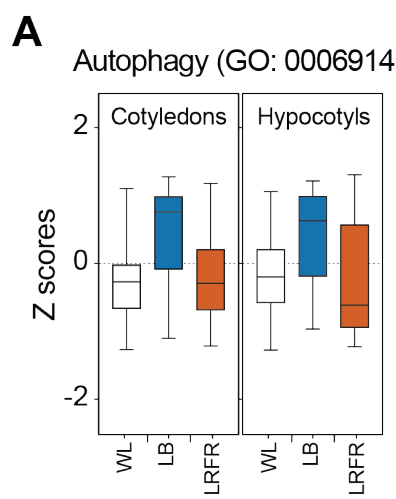

C

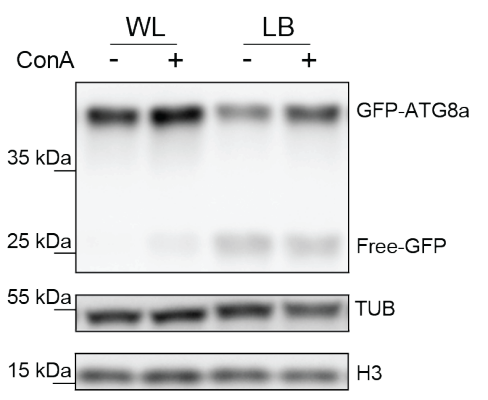

WL (Col-0)

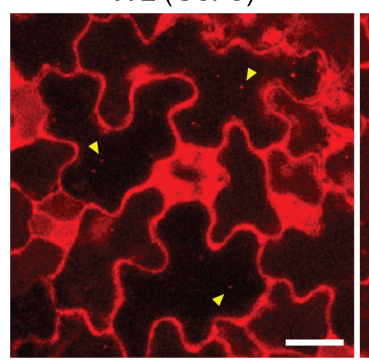

D
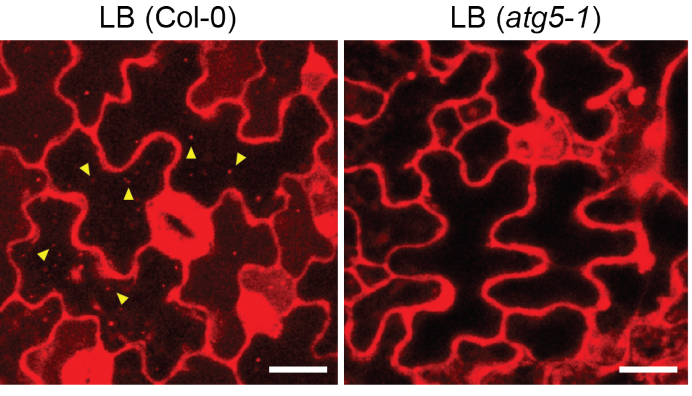

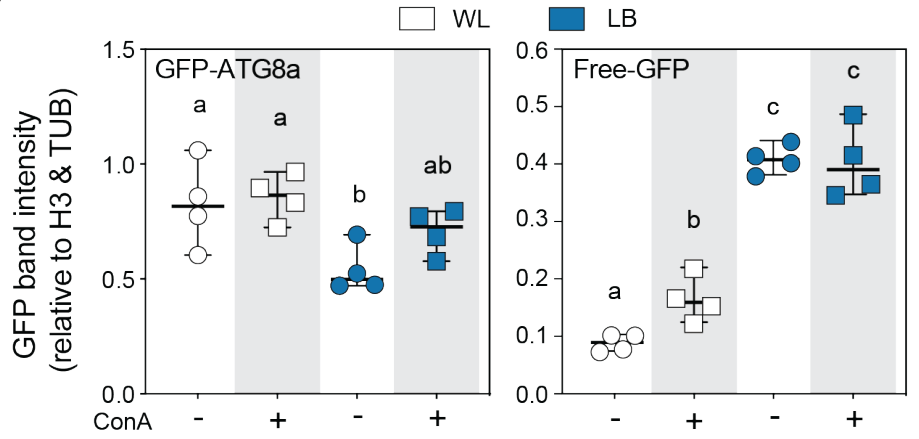

E

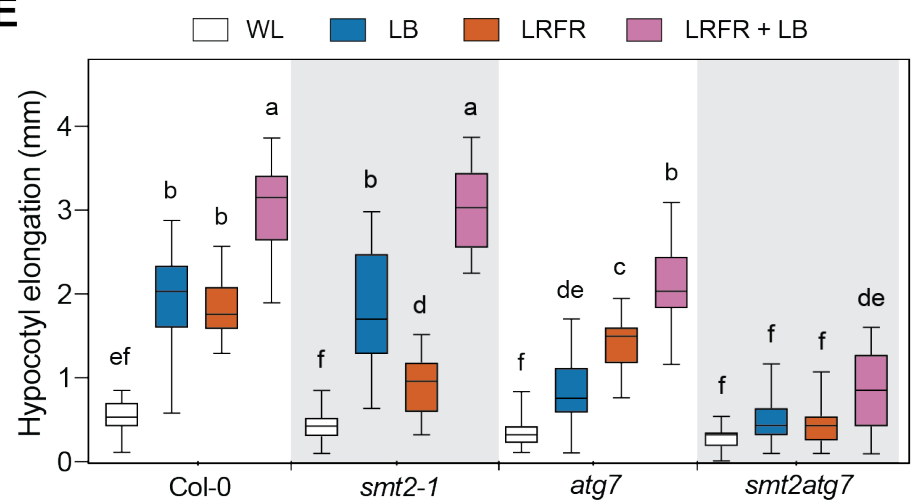

$\mathbf{F}$

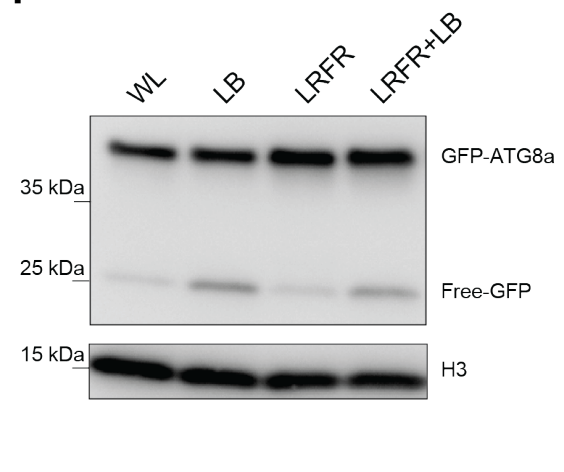

Figure 7. LB induces autophagy.

(A) Distributions of Z- scores computed from replicates averages for genes listed in autophagy GO term in Col-0 seedlings. (B) Cotyledon pavement cells expressing UBQ10::mCherry-ATG8e in the indicated backgrounds either kept in WL or treated with $8 \mathrm{~h}$ of LB in presence of concanamycin A (ConA, $5 \mu \mathrm{M})$. Yellow arrowheads indicate autophagic bodies. White bars equal to $20 \mu \mathrm{m}$. (C) Autophagic flux assay using 35S::GFP-ATG8a (WT). GFP-ATG8a and Free-GFP levels are detected in seedlings as treated as in (B) (ConA, $0.5 \mu \mathrm{M}$ ) with an anti-GFP antibody from total protein extract. (D) Quantification of GFP-ATG8a and Free-GFP bands in autophagic flux assays (C). Each data point indicates a biological replicate $(n=4$ biological with average of 2 technical replicates each), horizontal bar represents the median, whiskers extend to show the data range. (E) Hypocotyl elongation of the indicated genotypes $(n>12)$. (A, E) The horizontal bar represents the median; boxes extend from the 25th to the 75th percentile, whiskers extend to show the data range. (D, E) Different letters indicate significant difference $(\mathrm{P}<0.05$, two-way ANOVA with Tukey's HSD 
test). (F) GFP-ATG8a and Free-GFP levels are detected in seedlings treated as in (C) with the indicated light conditions. H3 (C, E) and TUB (C) were used as a loading control. The full list of genes in Autophagy GO term is given in Table S10. See also Figure S7.

\section{DISCUSSION}

In young seedlings, cotyledons are the major organs sensing LRFR while growth promotion occurs in hypocotyls (Kohnen et al., 2016, Procko et al., 2016, Procko et al., 2014). In the cotyledons, the PIF-YUC regulon controls production of auxin that promotes elongation upon transport to the hypocotyl. However, how PIFs control hypocotyl elongation locally (in the growing organ) and how PIF activity may be induced in the selfshaded hypocotyl is less clear. Modulation of auxin sensitivity in the hypocotyl appears to be one mechanism (Hersch et al., 2014, Hornitschek et al., 2012, Kohnen et al., 2016, Pucciariello et al., 2018) (Fig. 2C). Here, we show organ-specific transcriptional control of SMT2 and SMT3 by PIFs (Fig. 4B). ChIP data supports a direct role of PIF4 and PIF7 in the expression of those genes with enhanced binding to their promoter in LRFR (Fig. 4C, S4B). LRFR-induced SMT2 and SMT3 expression also depends on YUC-mediated auxin production (Fig. 4B), yet auxin alone does not induce their expression in hypocotyls (Chapman et al., 2012). This suggests a combined function of PIFs and auxin for LRFRinduced expression of SMT2 and SMT3. Similarly, the vast majority of LRFR-induced genes in the hypocotyl that belong to GO categories related to growth-promoting processes depend on both PIFs and YUCs (Fig. 2, Table S3). This regulatory pattern suggests that in the self-shaded hypocotyl, an increase in auxin rather than the photoconversion of phyB may regulate PIF-mediated gene expression. This hypothesis is consistent with coordinated regulation of growth-regulatory genes by ARF6, BZR1 and PIF4 (Oh et al., 2014). Furthermore, several PIFs are putative targets for ARF6 and BZR1 (Oh et al., 2014). BZR1 is also known to induce PIF4 expression during thermomorphogenesis (Ibanez et al., 2018) that induces hypocotyl elongation similarly to LRFR downstream of PIF4 and PIF7 (Chung et al., 2020, Fiorucci et al., 2019, Qiu, 2020). In contrast to hypocotyls, a substantial fraction of LRFR-induced genes in cotyledons depend on PIFs but not on YUCs (Fig. S2A). This is consistent with earlier studies identifying a number of LRFR-induced genes that do not depend on de novo auxin production (Tao et al., 2008). A change in light conditions in cotyledons leads to direct PIF activation potentially explaining these findings. 
Collectively, our data reveal organ-specific patterns of PIF-mediated gene induction in hypocotyls versus cotyledons and identify SMT2 as an example of a gene that is selectively induced in the hypocotyl and is required for LRFR-induced elongation.

In LRFR, SMT2 promotes hypocotyl elongation locally (Fig. 4, S4). Our data suggests that this is one example illustrating the need for enhanced PM lipid production to allow hypocotyl cell elongation. LRFR leads to reallocation of newly fixed carbon to the lipid fraction of $B$. rapa hypocotyls (de Wit et al., 2018). Transcriptome analysis indicates a global upregulation of sterol and sphingolipid biosynthetic genes by LRFR (Fig. 2C). Both lipid classes are major components of the PM (Mamode Cassim et al., 2019). PM extension depends on the deposition of lipids that occurs during the delivery of membranes via exocytosis (Boutté and Jaillais, 2020, Hepler et al., 2013, Mamode Cassim et al., 2019,

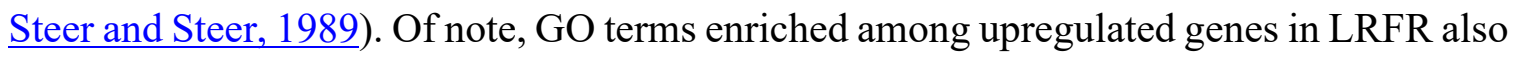
include endocytosis and exocytosis related terms (Fig. 1D). On the other hand, terms related to chloroplast lipids (GDG) are found among down-regulated genes in LRFR (Table S3). Consistent with the transcriptional data in Arabidopsis, PM lipids increase while chloroplast and storage lipids decrease in B. rapa hypocotyls (Fig. 6A). A similar decrease in chloroplasts was previously observed in tomato stems in LRFR (Cagnola et al., 2012). Moreover, we show that in Arabidopsis hypocotyls both chloroplasts and storage lipids decrease in LRFR (Fig 6B, C). Interestingly, during de-etiolation phytochromes are also known to control storage lipid utilisation (Kozuka et al., 2020). Overall, our data is consistent with LRFR leading to enhanced production of PM lipids and a reduction of other lipid classes (Fig. 6A). SMT2 and SMT3 act at a branch point of sterol biosynthesis (Fig. 4A). Their induction by LRFR may therefore also lead to changes in sterol composition which is potentially important given their role in PM fluidity and microdomain organisation (Mamode Cassim et al., 2019, Valitova et al., 2016). We currently cannot rule out this possibility, however our sterol measurements in LRFR-treated B. rapa do not provide strong evidence for such a change. We also note that given the global transcriptional upregulation of the sterol pathway (Fig. S4A), this is compatible with enhanced overall sterol demand but not necessarily indicative of changes in sterol composition. 
PIFs and auxin production are also functionally important for LB-induced hypocotyl elongation (de Wit et al., 2016, Keller et al., 2011, Keuskamp et al., 2011, Pedmale et al., 2016) (Fig. 1A). However, the majority of LB-regulated gene expression occurred in pif457 as in the WT (Fig. S1A). Furthermore, most of the PIF-dependent genes in LB, that represented only a small portion of LB regulated genes (Fig. 3A), are probably not direct PIF targets (Fig 3E, S3D, Table S6). Interestingly, many auxin, BR, and GA response and other growth related genes show lower basal (WL) expression in pif457 than in the WT and this difference persists in LB (Fig. 3, Table S5). Importantly, mutant analysis and pharmacological treatments show an indispensable role for auxin, BR and GA during LBinduced hypocotyl elongation (Fig 1A) (Keller et al., 2011, Keuskamp et al., 2011, Pedmale et al., 2016, Pierik et al., 2009). We thus conclude that pif457 gene expression in WL may contribute to the hypocotyl growth defect of the mutant in LB. This is also consistent with the report showing PIF4 and PIF5 are dose-dependent inducers of hypocotyl elongation in WL (Lorrain et al., 2008). It is however important to note that, hypocotyl elongation and PIF4 and PIF5 accumulation occurs slowly in LB compared to LRFR (Boccaccini et al., 2020, Lorrain et al., 2008, Pedmale et al., 2016, Pucciariello et al., 2018). Hence, our analysis at $3 \mathrm{~h}$ may have missed some of the PIF-regulated transcriptional events. Therefore, the link between PIF-regulated gene expression and hypocotyl growth control in LB require further investigations.

While LRFR leads to major transcriptional changes in the hypocotyl indicative of enhanced production of many building blocks required for growth, LB leads to the induction of many catabolic processes and autophagy related genes (Fig. 1D, S1C). The LRFR gene expression pattern suggests that when light resources are fully available (Fig. S7A), the Target of Rapamycin (TOR) pathway is on and promotes e.g. the biogenesis of ribosomes and nucleotides (Brunkard, 2020). The rapid and concomitant rise in auxin and many anabolic processes in hypocotyls (Fig. 1D, S1C) (Kohnen et al., 2016) suggest a potential link between these processes. In line with this, a recent report shows that sugar-dependent TOR activity requires auxin signalling (Van Leene et al., 2019). Unlike LRFR, LB leads to PAR reduction (Fig. S7A). Reduced PAR limits carbon fixation, including in conditions where only B light is decreased (Liu and van Iersel, 2021, Moraes et al., 2019). This is in 
line with gene expression patterns showing LB-specific reduction in carbon fixation and induction of starvation responses (Fig. 1D, S1C, Table S3, S4). This presumably includes metabolic adjustments including alternative pathways for respiration (e.g. protein catabolism) to sustain growth in LB in line with the previous reports in other carbon limiting conditions (Araujo et al., 2010, Izumi et al., 2013, Buchanan-Wollaston et al., 2005). When energy becomes scarce, autophagy-mediated recycling is promoted (Chen et al., 2019, Goto-Yamada et al., 2019, Li and Vierstra, 2012). Consistently, LB also transcriptionally promotes autophagy and leads to enhanced production of autophagic bodies and autophagic processing of GFP-ATG8a, while LRFR does not (Fig. 7). Moreover, the $\operatorname{atg} 7$ autophagy mutant had a particularly striking phenotype in LB-induced hypocotyl elongation while it was less affected in LRFR (Fig. 7E). Remarkably, this is the converse phenotype of $s m t 2$ mutants. Interestingly, the combined light treatment, which mimics vegetative shade, largely rescues the phenotypes of both single mutants, suggesting a degree of compensation between catabolic and anabolic processes. The smt 2 atg 7 double mutant phenotype with complete absence of elongation in LB and LRFR and only a modest response in combined treatments are in line with this conclusion (Fig. 7E). Importantly, SMT2 and SMT3 expression is induced in the hypocotyl of shade-treated seedlings (combined LB and LRFR) (Das et al., 2016). Altogether, our work indicates the requirement for enhanced de novo synthesis in LRFR and autophagy in LB, while the combination of both processes contributes to growth enhancement of the hypocotyl in vegetative shade.

In conclusion, our work shows that in vegetational shade that comprises a reduction in PAR and LRFR hypocotyl elongation requires autophagy and the induction of specific anabolic processes (e.g. sterol biosynthesis). In contrast, during neighbor proximity (LRFR only) growth enhancement relies on anabolic processes. We note that thermomorphogenesis and neighbor proximity both lead to similar growth adaptation using related signaling pathways (Casal and Balasubramanian, 2019, Qiu, 2020). Within a temperature range that does not significantly decrease photosynthetic efficiency, it is likely that for thermomorphogenesis as well the anabolic processes described here are relevant. 


\section{Acknowledgements}

We thank Martina Legris, Laure Allenbach Petrolati, Olivier Michaud, Mieke de Wit, Anupama Goyal, Ana Lopez Vazquez, Ganesh Mahadeo Nawkar and Maud Lagier for providing resources, technical support and/or comments on the manuscript; René Dreos for advice on statistical methods; Niko Geldner, Ersin Gül (ETH Zurich), Sinem Celebioven (University Zurich), Soner Yildiz (Icahn School of Medicine) and Yasin Dagdas (GMI, Vienna) for suggestions and comments on the manuscript; Christian Hardtke, Teva Vernoux (ENS Lyon), Richard Vierstra (Washington University, St Louis), Dany Geelen (University Gent) and Yasin Dagdas for providing resources. We are grateful to the CIF (https://cif.unil.ch/) for help with microscopy, the GTF (https://wp.unil.ch/gtf/) for RNA seq. experiments and the Metabolomics Unit (https://www.unil.ch/metabolomics/en/home.html) for the lipidomic analysis and the Bordeaux-Metabolome platform for analysis (https://www.biomemb.cnrs.fr/en/lipidomic-plateform/). Work in the Fankhauser lab is supported by the University of Lausanne and the Swiss National Science Foundation (310030B_179558), the Bordeaux Metabolome Facility-MetaboHUB by a grant from ANR (no. ANR-11-INBS-0010).

\section{Author contributions}

YCI: Conceptualization, Formal analysis, Data curation, Methodology, Investigation, Resources, Validation, Visualization, Writing - original draft. ASF, MT and VCG : Investigation, Resources, Validation. JK: Validation. SP and LW: Formal analysis, Data curation, Methodology. SM : Conceptualization, Data curation, Validation, Investigation, Methodology. LF and PVD : Investigation. JI and HGA: Investigation, Data curation, Validation. CF: Conceptualization, Data curation, Methodology, Project administration, Resources, Funding acquisition, Supervision, Validation, Writing original draft. All authors read and approved the manuscript. 


\section{RESOURCES AVAILABILITY}

\section{Lead Contact}

Further information and requests for resources and reagents should be directed to and will be fulfilled by the Lead Contact, Christian Fankhauser (Christian.fankhauser@unil.ch)

\section{Materials availability}

This study did not generate new unique reagents. Plasmids and transgenic plants generated in this study are available from the Lead Contact with a completed Materials Transfer Agreement.

\section{Data and code availability}

The RNA-seq data discussed in this publication have been deposited in NCBI's Gene Expression Omnibus (Edgar et al., 2002) and are accessible through GEO Series accession number GSE174655 (https://www.ncbi.nlm.nih.gov/geo/query/acc.cgi?acc=GSE174655).

\section{EXPERIMENTAL MODEL AND SUBJECT DETAILS}

\section{Plant material and growth conditions}

We used the Arabidopsis thaliana genotypes (cv Columbia-0) listed in key resources table. yuc2yuc5yuc8yuc9 was recrossed using all yuc alleles that are described in (Nozue et al., 2015) except yuc5-1 (SAIL_116_C0). We used the strain R-o-18 for $B$. rapa experiments. Oligonucleotides used for genotyping are listed in Table S11.

Seeds were size-selected and surface-sterilized using 70\% (v/v) ethanol and $0.05 \%$ (v/v) Triton X-100 for 3 min followed by 10 min incubation in 100\% (v/v) ethanol. Seeds were sowed on $1 / 2$ Murashige and Skoog medium ( $1 / 2 \mathrm{MS})$ containing $0.8 \%(\mathrm{w} / \mathrm{v})$ phytoagar (Agar-Agar, plant; Roth) and subsequently stratified at $4{ }^{\circ} \mathrm{C}$ for 3 day in darkness. For hypocotyl elongation and RNA-seq experiments where seedlings were 
grown on vertical plates the phytoagar concentration was raised to $1.6 \%(\mathrm{w} / \mathrm{v})(\underline{\text { Ince }}$ and Galvao, 2021). For all experiments, seedlings were grown in 16h/8h, light/dark photoperiod (LD) at $21^{\circ} \mathrm{C}$ in a Percival Scientific Model AR-22L (Perry, IA, USA) incubator. WL was emitted from white fluorescence tubes (Lumilux cool white $18 \mathrm{~W} / 840$ ) at a fluence rate of $130 \mu \mathrm{mol} \mathrm{m} \mathrm{m}^{-2} \mathrm{~s}^{-1}$ and LRFR was achieved by supplementing WL with $45 \mu \mathrm{mol} \mathrm{m} \mathrm{m}^{-2} \mathrm{~s}^{-1} \mathrm{FR}$ light (LEDs) lowering the R (640-700 $\mathrm{nm}) / \mathrm{FR}(700-760 \mathrm{~nm})$ from 1.4 to 0.2 , as measured by Ocean Optics USB2000+ spectrometer. A double layer of yellow filter (010 medium yellow, LEE Filters) lowering blue light from $7 \mu \mathrm{mol} \mathrm{m}^{-2} \mathrm{~s}^{-1}$ (WL) to $0.5 \mu \mathrm{mol} \mathrm{m} \mathrm{m}^{-2} \mathrm{~s}^{-1}$ (LB) was used to cover up the seedlings for LB treatments. The light spectra are shown in Figure S7A.

For hypocotyl elongation and microscopy experiments seedlings were grown for 4 days in WL and subsequently kept in WL or transferred to light treatment (at ZT2) for additional 3 days. Figure 1A was an exception where seedlings were grown for 5 days in WL and subsequently kept in WL or transferred to light treatment (at ZT2) for additional 3 days. Pharmacological treatments (fenpropimorph and picloram) were done on vertically grown seedlings on nylon meshes. After 4 days in WL seedlings on nylon meshes were transferred to new plates containing the drug or the corresponding solvent and put for 3 additional days into WL or light treatment (at ZT2). Fenpropimorph (Carbosynth, United Kingdom, FF23264), picloram (Sigma-Aldrich, Steinheim, Germany, P5575), and Concanamycin A (Sigma-Aldrich, Steinheim, Germany, C9705) were dissolved in DMSO (dimethylsulfoxide) applied at the indicated concentrations in Figure legends (DMSO for mock).

For RNA-seq and western blot experiments seedlings were grown for 5 days in WL and subsequently kept in WL or transferred to light treatment (at ZT2) for 3h (RNA-seq) or $8 \mathrm{~h}$ (western blots) before harvesting. For concanamycin A treatment, seedlings were transferred to liquid $1 / 2 \mathrm{MS}$ with shaking (75 rpm).

For ChIP-qPCR experiments, seedlings were grown in WL for 5 days and then either kept in WL or transferred to LRFR (at ZT2) for additional 5 days before harvesting. For RT-qPCR, complex lipid and sterol measurement analysis, B. rapa seedlings were grown for 5 days in WL and subsequently kept in WL or transferred to LRFR (at ZT2) for the indicated time in legends before harvesting. 
Seedlings imaging and measurements were described previously (Ince and Galvao, 2021). In short, hypocotyl length was measured from images before (day 4) and after the treatments (day 7). Hypocotyl elongation for each individual seedling is calculated by subtracting the length at $4 \mathrm{~d}$ from the length at $7 \mathrm{~d}$..

\section{METHOD DETAILS}

\section{Constructs cloning}

PCR amplifications were performed using Phusion ${ }^{\circledR}$ High-Fidelity DNA Polymerase (New England Biolabs, Massachusetts, USA, Cat. No. M0530). All cloning was done using In Fusion ${ }^{\circledR}$ HD Cloning kit (Takara, California, USA; Cat. No. 639649). First, GUSPlus::tOCS was cloned in pFP100 plasmid carrying pAt2S3::GFP selection marker (Bensmihen et al., 2004) and the new plasmid was named as pYI001. pFR06 and $p$ GH3.17 were cloned into pYI001 in order to obtain pFRO6::GUSPlus::tOCS and pGH3.17::GUSPlus::tOCS, respectively. pUBQ10::SMT2-Flag::tOCS was cloned into $p$ FP100, while pFRO6::SMT2-Flag, and pGH3.17::SMT2-Flag were cloned into pYI001. The primers are listed in Table S11. These constructs were transformed into smt2-1 plants using Agrobacterium tumefaciens GV3301 strain by floral dip (Clough and Bent, 1998).

\section{RNA isolation, quantitative RT-PCR and RNA-sequencing}

For RNA isolation, 5d-old seedlings were harvested in liquid nitrogen and kept at -70 ${ }^{\circ} \mathrm{C}$ for overnight. Next day, seedlings were covered with $-70{ }^{\circ} \mathrm{C}$ cold RNAlater ${ }^{\mathrm{TM}}-\mathrm{ICE}$ (Thermo Fisher Scientific, United States, AM7030) and transferred to $-20^{\circ} \mathrm{C}$ overnight. Cotyledons and hypocotyls were dissected using sharp needles on top of an ice block under a binocular microscope (Nikon, SMZ1500) and RNA isolation and reverse transcription quantitative polymerase chain reaction (RT-qPCR) reactions were performed as previously described (Kohnen et al., 2016). Oligonucleotides are listed in Table S11.

For RNA-sequencing, RNA quality was assessed on a Fragment Analyzer (Agilent Technologies). From 40 ng total RNA, mRNA was isolated with the NEBNext Poly(A) mRNA Magnetic Isolation Module. RNA-seq libraries were then prepared from the 
mRNA using the NEBNext Ultra II Directional RNA Library Prep Kit for Illumina (New England Biolabs, Massachusetts, USA). Libraries were quantified by a fluorimetric method and their quality assessed on a Fragment Analyzer (Agilent Technologies). Cluster generation was performed with the resulting libraries using Illumina HiSeq 3000/4000 SR Cluster Kit reagents. Libraries were sequenced on the Illumina HiSeq 4000 with HiSeq 3000/4000 SBS Kit reagents for 150 cycles. Sequencing data were demultiplexed with the bcl2fastq Conversion Software (v. 2.20, Illumina; San Diego, California, USA).

\section{ChIP-qPCR}

10d-old seedlings PIF4p::PIF4-HA in pif4-101 (Zhang et al., 2017) and PIF7p::PIF7$H A$ in pif7-2 seedlings (Galvao et al., 2019) grown in WL for five days and then either kept in WL or transferred to LRFR for another five days were harvested in liquid nitrogen. Chromatin extraction was performed as described previously (Bourbousse et al., 2018) except that samples were cross-linked only with formaldehyde. Immunoprecipitation was performed as described previously (Gendrel et al., 2005) using an anti-HA antibody (Santa Cruz Biotechnology, Inc., Dallas, TX, USA; sc-7392 X). The qPCR was done in triplicates or quadruplicate on input and immunoprecipitated DNA. Peaks (P) were defined using a genome-wide ChIP study from etiolated seedlings that identified PIF4-peaks ( $\underline{\text { Oh et al., 2012) }}$. Controls (C) are on coding regions of each gene. Oligonucleotides are listed in Table S11.

\section{Western-blot analysis}

Total protein extracts from seedlings were obtained as previously described (Galvao et al., 2019). Protein samples were separated on 10\% Mini-Protean TGX gels (Bio-Rad, Hercules, CA, USA) and blotted on nitrocellulose membrane (Bio-Rad) using Turbo transfer system (Bio-Rad). Membranes were blocked with $5 \%$ milk overnight at $4^{\circ} \mathrm{C}$ or $1 \mathrm{~h}$ at room temperature for Anti-GFP JL-8 (1:4000; Clontech, California, USA; Cat. No. 632380/632381), polyclonal H3 (1:2000; Abcam, Cambridge, UK; Cat. No.1791), Anti-TUB (1:2000; Abicode, California, USA, Cat. No. M0267-1a) antibodies before probing with horseradish peroxidase (HRP)-conjugated anti-rabbit (for H3) or anti- 
mouse (for anti-GFP and anti-TUB) as the secondary antibody (1:5000; Promega, Madison, USA; Cat. No. W4011 and W4021, respectively). Chemiluminescence signal were obtained with Immobilon Western Chemiluminescent HRP Substrate (Millipore, Merck KGaA, Darmstadt, Germany) on an ImageQuant LAS 4000 mini (GE Healthcare, Buckinghamshire, UK). Images were processed with ImageJ software (http://rsb.info.nih.gov/ij).

\section{Microscopy and GUS Staining}

DII-Venus microscopy and image quantification were performed as indicated in (Kohnen et al., 2016). In short, 4-day-old seedlings grown as described above were transferred to LRFR or kept in WL for $1 \mathrm{~h}$ before imaging. We used an inverted Zeiss confocal microscope (LSM 710, 20X objective, 0.8 DIC). VENUS signal was detected using an Argon laser (excitation at $514 \mathrm{~nm}$ and band pass emission between 520 and $560 \mathrm{~nm}$ ). Image stacks (5-6/seedling) were acquired for every hypocotyl until the VENUS signal was lost. The pinhole was opened to collect the maximal signal intensity together with the minimal stack number (5.42 airy units, $20.2 \mu \mathrm{m}$ section, $10.08 \mu \mathrm{m}$ interval). Images were processed with ImageJ software (http://rsb.info.nih.gov/ij). To quantify the VENUS signal, we used the SUM slices projection of 4 slices from the stack excluding the first layer with the stomata.

For the lipid droplet (LD) quantification, 4-day-old seedlings grown as described above were transferred to LRFR or kept in WL. Seedlings were treated with BODIPY TM 493/503 (2 $\mu \mathrm{g} / \mathrm{mL}$ in $\left.\mathrm{H}_{2} \mathrm{O}\right)$ for $20 \mathrm{~min}$ at room temperature and imaged on inverted Zeiss confocal microscope (LSM 710, 20X objective, 0.8 DIC) 30h after the beginning of light treatment. BODIPY тм 493/503 signal was detected using an Argon laser (excitation at $488 \mathrm{~nm}$ and band pass emission between 500 to $540 \mathrm{~nm}$ ). Image stacks (6/seedling) were acquired for every hypocotyl. The pinhole was opened to 3.15 Airy Units (11.4 $\mu \mathrm{m}$ section, $10.00 \mu \mathrm{m}$ interval). Images were processed with ImageJ software (http://rsb.info.nih.gov/ij). To quantify the signal, we selected a region of interest (ROI) on the upper half of the hypocotyls and analyzed the fluorescence intensity of particles (size $=0-75$ circularity $=0.50-1.00$ ) in each image stack with a threshold (>3000) and summed the total intensity using the "Analyze particles" tool. 
For chloroplast quantification, we used the same protocol as the LD quantification with the following changes. We used a HeNe633 laser (excitation at $633 \mathrm{~nm}$ and band pass emission between 640 to $685 \mathrm{~nm}$ to have an equal contribution from ChlA and ChlB). The pinhole was opened to 3.15 Airy Units (11.4 $\mu \mathrm{m}$ section, $10.00 \mu \mathrm{m}$ interval). Threshold was adjusted to $>10000$; size and circularity were kept as default ( 0 -infinity and 0-100, respectively) in ImageJ.

For visualization of autophagic bodies in UBQ10::mCherry-ATG8e lines ( $\mathrm{Hu}$ et al., 2020, Stephani et al., 2020), we used the following settings. 4-day-old seedlings grown as described above were transferred to LB or kept in WL for $8 \mathrm{~h}$ before imaging in the presence $(5 \mu \mathrm{M})$ or absence (DMSO) of concanamycin A (Sigma-Aldrich, Steinheim, Germany, C9705). We used DPSS 561-10 laser (excitation at $561 \mathrm{~nm}$ and band pass emission between 570 to $635 \mathrm{~nm}$ ) (LSM 710, 63X objective, 1.3 oil DIC). The pinhole was opened to 5.32 Airy Units $(4.3 \mu \mathrm{m}$ section, $4.21 \mu \mathrm{m}$ interval). 2 stacks are combined for each image.

The protocol for GUS staining reactions was described in (Galvao et al., 2019). Cotyledons were prepared for cotyledon vasculature imaging as described in (Carland, 2002). GUS staining and cotyledon vasculature were imaged using a dissecting microscope (Nikon SMZ1500).

\section{Sterol measurements}

4 hypocotyls from $5 \mathrm{~d}$-old $B$. rapa seedlings per sample were pooled and frozen in liquid nitrogen immediately after fresh weights were recorded. Samples were heated for $1 \mathrm{~h}$ in EtOH with $1 \% \mathrm{H}_{2} \mathrm{SO}_{4}$ at $85^{\circ} \mathrm{C}$. Sterols were extracted in hexane. Free hydroxyl groups were derivatized at $110^{\circ} \mathrm{C}$ for $30 \mathrm{~min}$, surplus BSTFA-trimethylchlorosilane (SigmaAldrich, Steinheim, Germany, Cat. No. B-023) was evaporated and samples were dissolved in hexane for analysis using GC-MS (Agilent 7890, A coupled to a mass spectrometer, MSD 5975, Agilent EI) under the same conditions as described (Cacas et al., 2016). Quantification of sterols was based on peak areas, which were derived from total ion current and using cholestanol as internal standard. Each sterol was normalized to the total amount of detected sterols and presented as percentage of total. 


\section{Untargeted lipidomics mass spectrometry analysis}

4 hypocotyls from 5d-old $B$. rapa seedlings per sample are pooled and preheated isopropanol (at $75^{\circ} \mathrm{C}$ ) was added immediately after fresh weights are recorded. Each sample with isopropanol was incubated at $75^{\circ} \mathrm{C}$ for $15 \mathrm{~min}$ to inhibit phospholipase activity and cooled down to room temperature. Samples were kept at $4{ }^{\circ} \mathrm{C}$ overnight and isopropanol was then evaporated to dryness using Nitrogen steam. Dry extracts were then reconstituted in $200 \mu \mathrm{L}$ of IPA spiked with the internal standard mixture (SPLASH® LIPIDOMIX ${ }^{\circledR}$ Mass Spec Standard (92/8; v/v)). This solution was further homogenized in the Cryolys Precellys 24 sample Homogenizer $(2 \times 20$ seconds at 10000 rpm, Bertin Technologies, Rockville, MD, US) with ceramic beads. The bead beater was air-cooled down at a flow rate of $110 \mathrm{~L} / \mathrm{min}$ at 6 bar. Homogenized extracts were centrifuged for 15 minutes at $21000 \mathrm{~g}$ at $4^{\circ} \mathrm{C}$ (Hermle, Gosheim, Germany) and the resulting supernatant was collected and transferred to an LC-MS vial.

Extracted samples were analyzed by reversed phase liquid chromatography coupled to a high-resolution mass spectrometry (RPLC-HRMS) instrument (Agilent 6550 IonFunnel QTOF).SEp In both, positive and negative ionization mode, the chromatographic separation was carried out on a Zorbax Eclipse Plus C18 (1.8 $\mu \mathrm{m}, 100$ $\mathrm{mm} \times 2.1 \mathrm{~mm}$ I.D. column) (Agilent technologies, USA). Mobile phase was composed of $\mathrm{A}=60: 40(\mathrm{v} / \mathrm{v})$ Acetonitrile:water with $10 \mathrm{mM}$ ammonium acetate and $0.1 \%$ acetic acid and $\mathrm{B}=88: 10: 2$ Isopropanol:acetonitrile:water with $10 \mathrm{mM}$ ammonium acetate and $0.1 \%$ acetic acid. The linear gradient elution from $15 \%$ to $30 \% \mathrm{~B}$ was applied for 2 minutes, then from $30 \%$ to $48 \%$ B for 0.5 minutes, from $48 \%$ to $72 \%$ B and last gradient step from $72 \%$ to $99 \%$ B followed by 0.5 minutes isocratic conditions and a 3 min re-equilibration to the initial chromatographic conditions. The flow rate was 600 $\mu \mathrm{L} / \mathrm{min}$, column temperature $60^{\circ} \mathrm{C}$ and sample injection volume $2 \mu \mathrm{l}$.

ESI source conditions were set as follows: dry gas temperature $200{ }^{\circ} \mathrm{C}$, nebulizer 35 psi and flow $14 \mathrm{~L} / \mathrm{min}$, sheath gas temperature $300{ }^{\circ} \mathrm{C}$ and flow $11 \mathrm{~L} / \mathrm{min}$, nozzle voltage $1000 \mathrm{~V}$, and capillary voltage +/- $3500 \mathrm{~V}$. Full scan acquisition mode in the mas range of $100-1700 \mathrm{~m} / \mathrm{z}$ was applied for MS1 data acquisition while MS/MS data were acquired in the iterative data dependent acquisition mode to facilitate lipid identification and annotation. 
Pooled QC samples (representative of the entire sample set) were analyzed periodically (every 6 samples) throughout the overall analytical run in order to assess the quality of the data, correct the signal intensity drift and remove the non-reproducible signals (CV $>25 \%$ ) (Dunn et al., 2011). In addition, a series of diluted quality controls (dQC) were prepared by dilution with isopropanol: 100\% QC, 50\%QC, 25\%QC, $12.5 \% \mathrm{QC}$ and $6.25 \% \mathrm{QC}$ and analyzed at the beginning and at the end of the sample batch. This QC dilution series served as a linearity filter to remove the features that do not respond linearly (correlation with dilution factor is < 0.65) (Gagnebin et al., 2017).

\section{Data processing}

Raw LC-HRMS and HR(MS/MS) data was processed using MS-Dial software (Tsugawa et al., 2015)

(http://prime.psc.riken.jp/Metabolomics_Software/MS-DIAL/). Relative quantification of lipids was based on EIC (Extracted Ion Chromatogram) areas for the monitored precursor ions at the MS1 level. Peak areas were normalized considering the sample amount (mg) (full lists of lipid species are given in Table S9). The obtained tables (containing peak areas of detected and identified lipids by MS and MS/MS, and using MS only across all samples) were exported to "R" software http://cran.rproject.org/ where the signal intensity drift correction was done within the LOWESS/Spline normalization program (Tsugawa et al., 2015) followed by noise filtering (CV (QC features) > 30\%) and visual inspection of linear response.

The abundance of each MS/MS detected lipid species was normalized to the total amount of MS/MS detected lipids and presented as a percentage of total.

\section{QUANTIFICATION AND STATISTICAL ANALYSES}

RNA-seq initial data analysis

Purity-filtered reads were adapters and quality trimmed with Cutadapt (v. 1.8) (Martin, 2011). Reads matching to ribosomal RNA sequences were removed with fastq_screen (v. 0.11.1). Remaining reads were further filtered for low complexity with reaper (v. 15-065) (Davis et al., 2013). More than 30 million uniquely mapped reads were obtained per library and reads were aligned against the Arabidopsis thaliana.TAIR10.39 genome using STAR (v. 2.5.3a) (Dobin et al., 2013). The number 
of read counts per gene locus was summarized with htseq-count (v. 0.9.1) (Anders et al., 2015) using the Arabidopsis thaliana.TAIR10.39 gene annotation. Quality of the RNA-seq data alignment was assessed using RSeQC (v. 2.3.7) (Wang et al., 2012).

Statistical analysis was performed for genes independently in R ( $\mathrm{R}$ version 4.0.2). All steps described here were performed separately for the samples from hypocotyls and cotyledons (except for the initial clustering of all samples together). Genes with low counts were filtered out according to the rule of 1 count(s) per million (cpm) in at least 1 sample. The number of genes retained in the analyses based on this filtering is different for hypocotyls and cotyledons. Library sizes were scaled using TMM normalization. Subsequently, the normalized counts were transformed to cpm values and a $\log 2$ transformation was applied by means of the function cpm with the parameter setting prior.counts $=1$ (edgeR) (

Differential expression was computed with the R Bioconductor package "limma" (Ritchie et al., 2015) by fitting data to a linear model. The approach limma-trend was used. Fold changes were computed and a moderated t-test was applied. P-values were adjusted using the Benjamini-Hochberg (BH) method, which controls for the false discovery rate (FDR), globally across several comparisons of experimental conditions. The adjustment was performed in a few different ways customized to different parts of the data analysis. For Table S1, Figure 1, and Figure S1, p-values were adjusted globally across pairs of comparisons, LB vs. WL and LRFR vs. WL in each genotype separately. For Table S5, Figure 3, and Figure S3, p-values were adjusted globally across three comparisons between different genotypes while keeping the light condition (WL) unchanged: pif457 vs Col-0, yuc2589 vs Col-0 and smt2-1 vs Col-0. For Table S3, Table S4, Figure 2, Figure S2, Figure 3, and Figure S3, F-tests were used that yielded a single $\mathrm{p}$-value for three comparisons, and post-hoc testing as implemented the $\mathrm{R}$ package limma was then applied to identify significantly regulated genes per comparison. For Figure S5, the same F-test is applied for two comparisons.

Gene set enrichment analysis for Gene Ontology

Gene set enrichment analysis were conducted with ShinyGO v0.61:Gene Ontology Enrichment Analysis + more (http://bioinformatics.sdstate.edu/go/) (Ge et al., 2020) in Arabidopsis thaliana using a P-value cutoff (FDR) 0.05 and 500 most significant terms 
to show. The networks of enriched GO categories were visualized with $\mathrm{R}$ software (https://www.r-project.org/) using "visNetwork" and "igraph" libraries. Two terms (nodes) were connected if they share $20 \%$ or more genes. The size of the nodes indicates fold change for each term. We highlighted selected terms for each organ and light condition that we could easily relate to growth regulation (Fig 1D, S1C). The highlighted terms are not necessarily the most significant ones (full lists are available in Table $\mathrm{S} 2$ and as interactive versions).

Statistical Motif Analysis in Promoter or Upstream Gene Sequences

Motif enrichment analyses were conducted with TAIR's Motif Analysis tool (https://www.arabidopsis.org/tools/bulk/motiffinder/index.jsp) using $1 \mathrm{~kb}$ upstream sequences.

Other statistical analyses and data representation

For all the phenotypic analyses of hypocotyl elongation and the quantification of DIIsignal, we performed two-way analysis of variance (ANOVA) (aov) and computed Tukey's Honest Significance Differences (HSD) test (“agricolae” package) with default parameters using R software (https://www.r-project.org/). For phenotypic analysis of treatments to fenpropimorph and picloram, we performed two-way analysis of variance (ANOVA) (aov) and represented the significance as genotype*drug interaction in the given light conditions. For the comparisons including qPCR, ChIP-qPCR, sterol measurements, and lipidomics analysis, autophagic flux assays, we performed Student's T-test. For lipidomics analysis, we further applied a BH correction for $\mathrm{p}$ values. We used binomial distribution for the PIF4 target enrichment, promoter motif, and to determine the significance of PIFs and/or YUCs dependence of enriched GO terms in given light conditions (Table S3, S4, S5).

In boxplots, the horizontal bar represents the median; boxes extend from the 25 th to the 75th percentile, whiskers extend to show data range. In bar charts data are shown as the means \pm standard deviation (SD). Autophagic flux assays are given as individual values from 4 biological replicates (average of 2 technical replicates), the horizontal lines indicate median, error bars extend to show data range. For the fenpropimorph and picloram treatments, the data show the means \pm SD with a simple linear regression line connecting data points for the given light condition and the genotype. Asterisks (*) and 
bioRxiv preprint doi: https://doi.org/10.1101/2021.06.16.448628; this version posted June 17, 2021. The copyright holder for this preprint (which was not certified by peer review) is the author/funder, who has granted bioRxiv a license to display the preprint in perpetuity. It is made available under aCC-BY-NC-ND 4.0 International license.

different letters in the graphs indicate significant difference as defined by the statistical methods described above $(\mathrm{P}<0.05)$. 


\section{References}

ALDANA, J., ROMERO-OTERO, A. \& CALA, M. P. 2020. Exploring the Lipidome: Current Lipid Extraction Techniques for Mass Spectrometry Analysis. Metabolites, 10, doi:10.3390/metabo10060231.

ANDERS, S., PYL, P. T. \& HUBER, W. 2015. HTSeq--a Python framework to work with high-throughput sequencing data. Bioinformatics, 31, 166-9, doi:10.1093/bioinformatics/btu638.

ARAUJO, W. L., ISHIZAKI, K., NUNES-NESI, A., LARSON, T. R., TOHGE, T., KRAHNERT, I., WITT, S., OBATA, T., SCHAUER, N., GRAHAM, I. A., LEAVER, C. J. \& FERNIE, A. R. 2010. Identification of the 2-hydroxyglutarate and isovaleryl-CoA dehydrogenases as alternative electron donors linking lysine catabolism to the electron transport chain of Arabidopsis mitochondria. Plant Cell, 22, 1549-63, doi:10.1105/tpc.110.075630.

BALLARE, C. L. \& PIERIK, R. 2017. The shade-avoidance syndrome: multiple signals and ecological consequences. Plant Cell Environ, 40, 2530-2543, doi:10.1111/pce.12914.

BENSMIHEN, S., TO, A., LAMBERT, G., KROJ, T., GIRAUDAT, J. \& PARCY, F. 2004. Analysis of an activated ABI5

allele using a new selection method for transgenic Arabidopsis seeds. FEBS Letters, 561, 127-131, doi:10.1016/s0014-5793(04)00148-6.

BOCCACCINI, A., LEGRIS, M., KRAHMER, J., ALLENBACH-PETROLATI, L., GOYAL, A., GALVAN-AMPUDIA, C., VERNOUX, T., KARAYEKOV, E., CASAL, J. J. \& FANKHAUSER, C. 2020. Low Blue Light Enhances Phototropism by Releasing Cryptochrome1-Mediated Inhibition of PIF4 Expression. Plant Physiol, 183, 1780-1793, doi:10.1104/pp.20.00243.

BOU-TORRENT, J., GALSTYAN, A., GALLEMI, M., CIFUENTES-ESQUIVEL, N., MOLINA-CONTRERAS, M. J., SALLA-MARTRET, M., JIKUMARU, Y., YAMAGUCHI, S., KAMIYA, Y. \& MARTINEZ-GARCIA, J. F. 2014. Plant proximity perception dynamically modulates hormone levels and sensitivity in Arabidopsis. J Exp Bot, 65, 2937-47, doi:10.1093/jxb/eru083.

BOURBOUSSE, C., VEGESNA, N. \& LAW, J. A. 2018. SOG1 activator and MYB3R repressors regulate a complex DNA damage network in Arabidopsis. Proc Natl Acad Sci U S A, 115, E12453-E12462, doi:10.1073/pnas.1810582115.

BOUTTÉ, Y. \& JAILLAIS, Y. 2020. Metabolic Cellular Communications: Feedback Mechanisms between Membrane Lipid Homeostasis and Plant Development. Developmental Cell, doi:10.1016/j.devcel.2020.05.005.

BRUNKARD, J. O. 2020. Exaptive Evolution of Target of Rapamycin Signaling in Multicellular Eukaryotes. Dev Cell, 54, 142-155, doi:10.1016/j.devcel.2020.06.022.

BRUNOUD, G., WELLS, D. M., OLIVA, M., LARRIEU, A., MIRABET, V., BURROW, A. H., BEECKMAN, T., KEPINSKI, S., TRAAS, J., BENNETT, M. J. \& VERNOUX, T. 2012. A novel sensor to map auxin response and distribution at high spatio-temporal resolution. Nature, 482, 103-6, doi:10.1038/nature10791.

BUCHANAN-WOLLASTON, V., PAGE, T., HARRISON, E., BREEZE, E., LIM, P. O., NAM, H. G., LIN, J. F., WU, S. H., SWIDZINSKI, J., ISHIZAKI, K. \& 
LEAVER, C. J. 2005. Comparative transcriptome analysis reveals significant differences in gene expression and signalling pathways between developmental and dark/starvation-induced senescence in Arabidopsis. Plant J, 42, 567-85, doi:10.1111/j.1365-313X.2005.02399.x.

BUTI, S., HAYES, S. \& PIERIK, R. 2020. The bHLH network underlying plant shadeavoidance. Physiol Plant, 169, 312-324, doi:10.1111/ppl.13074.

CACAS, J. L., BURE, C., GROSJEAN, K., GERBEAU-PISSOT, P., LHERMINIER, J., ROMBOUTS, Y., MAES, E., BOSSARD, C., GRONNIER, J., FURT, F., FOUILLEN, L., GERMAIN, V., BAYER, E., CLUZET, S., ROBERT, F., SCHMITTER, J. M., DELEU, M., LINS, L., SIMON-PLAS, F. \& MONGRAND, S. 2016. Revisiting Plant Plasma Membrane Lipids in Tobacco: A Focus on Sphingolipids. Plant Physiol, 170, 367-84, doi:10.1104/pp.15.00564.

CAGNOLA, J. I., PLOSCHUK, E., BENECH-ARNOLD, T., FINLAYSON, S. A. \& CASAL, J. J. 2012. Stem transcriptome reveals mechanisms to reduce the energetic cost of shade-avoidance responses in tomato. Plant Physiol, 160, 1110 9, doi:10.1104/pp.112.201921.

CARLAND, F., FUJIOKA, S. \& NELSON, T. 2010. The sterol methyltransferases SMT1, SMT2, and SMT3 influence Arabidopsis development through nonbrassinosteroid products. Plant Physiol, 153, 741-56, doi:10.1104/pp.109.152587.

CARLAND, F. \& NELSON, T. 2009. CVP2- and CVL1-mediated phosphoinositide signaling as a regulator of the ARF GAP SFC/VAN3 in establishment of foliar vein patterns. Plant J, 59, 895-907, doi:10.1111/j.1365-313X.2009.03920.x.

CARLAND, F. M. 2002. The Identification of CVP1 Reveals a Role for Sterols in Vascular Patterning. The Plant Cell Online, 14, 2045-2058, doi: $10.1105 /$ tpc.003939.

CASAL, J. J. 2013. Photoreceptor signaling networks in plant responses to shade. Annu Rev Plant Biol, 64, 403-27, doi:10.1146/annurev-arplant-050312-120221.

CASAL, J. J. \& BALASUBRAMANIAN, S. 2019. Thermomorphogenesis. Annu Rev Plant Biol, doi:10.1146/annurev-arplant-050718-095919.

CHAPMAN, E. J., GREENHAM, K., CASTILLEJO, C., SARTOR, R., BIALY, A., SUN, T. P. \& ESTELLE, M. 2012. Hypocotyl transcriptome reveals auxin regulation of growth-promoting genes through GA-dependent and -independent pathways. PLoS One, 7, e36210, doi:10.1371/journal.pone.0036210.

CHEN, Q., SHINOZAKI, D., LUO, J., POTTIER, M., HAVE, M., MARMAGNE, A., REISDORF-CREN, M., CHARDON, F., THOMINE, S., YOSHIMOTO, K. \& MASCLAUX-DAUBRESSE, C. 2019. Autophagy and Nutrients Management in Plants. Cells, 8, doi:10.3390/cells8111426.

CHUNG, B. Y. W., BALCEROWICZ, M., DI ANTONIO, M., JAEGER, K. E., GENG, F., FRANASZEK, K., MARRIOTT, P., BRIERLEY, I., FIRTH, A. E. \& WIGGE, P. A. 2020. An RNA thermoswitch regulates daytime growth in Arabidopsis. Nature Plants, doi:10.1038/s41477-020-0633-3.

CIFUENTES-ESQUIVEL, N., BOU-TORRENT, J., GALSTYAN, A., GALLEMI, M., SESSA, G., SALLA MARTRET, M., ROIG-VILLANOVA, I., RUBERTI, I. \& MARTINEZ-GARCIA, J. F. 2013. The bHLH proteins BEE and BIM positively 
modulate the shade avoidance syndrome in Arabidopsis seedlings. Plant J, 75, 989-1002, doi:10.1111/tpj.12264.

CLOUGH, S. J. \& BENT, A. F. 1998. Floral dip: a simplified method for Agrobacterium-mediated transformation of Arabidopsis thaliana. Plant J, 16, 735 43, doi:10.1046/j.1365-313x.1998.00343.x.

DAS, D., ST ONGE, K. R., VOESENEK, L. A., PIERIK, R. \& SASIDHARAN, R. 2016. Ethylene- and Shade-Induced Hypocotyl Elongation Share Transcriptome Patterns and Functional Regulators. Plant Physiol, 172, 718-733, doi:10.1104/pp.16.00725.

DAVIS, M. P., VAN DONGEN, S., ABREU-GOODGER, C., BARTONICEK, N. \& ENRIGHT, A. J. 2013. Kraken: a set of tools for quality control and analysis of high-throughput sequence data. Methods, 63, 41-9, doi:10.1016/j.ymeth.2013.06.027.

DE WIT, M., GEORGE, G. M., INCE, Y. C., DANKWA-EGLI, B., HERSCH, M., ZEEMAN, S. C. \& FANKHAUSER, C. 2018. Changes in resource partitioning between and within organs support growth adjustment to neighbor proximity in Brassicaceae seedlings. Proc Natl Acad Sci U S A, 115, E9953-E9961, doi:10.1073/pnas.1806084115.

DE WIT, M., KEUSKAMP, D. H., BONGERS, F. J., HORNITSCHEK, P., GOMMERS, C. M. M., REINEN, E., MARTINEZ-CERON, C., FANKHAUSER, C. \& PIERIK, R. 2016. Integration of Phytochrome and Cryptochrome Signals Determines Plant Growth during Competition for Light. Curr Biol, 26, 33203326, doi:10.1016/j.cub.2016.10.031.

DE WIT, M., LJUNG, K. \& FANKHAUSER, C. 2015. Contrasting growth responses in lamina and petiole during neighbor detection depend on differential auxin responsiveness rather than different auxin levels. New Phytol, 208, 198-209, doi:10.1111/nph.13449.

DOBIN, A., DAVIS, C. A., SCHLESINGER, F., DRENKOW, J., ZALESKI, C., JHA, S., BATUT, P., CHAISSON, M. \& GINGERAS, T. R. 2013. STAR: ultrafast universal RNA-seq aligner. Bioinformatics, 29, 15-21, doi:10.1093/bioinformatics/bts635.

DUNN, W. B., BROADHURST, D., BEGLEY, P., ZELENA, E., FRANCISMCINTYRE, S., ANDERSON, N., BROWN, M., KNOWLES, J. D., HALSALL, A., HASELDEN, J. N., NICHOLLS, A. W., WILSON, I. D., KELL, D. B., GOODACRE, R. \& HUMAN SERUM METABOLOME, C. 2011. Procedures for large-scale metabolic profiling of serum and plasma using gas chromatography and liquid chromatography coupled to mass spectrometry. Nat Protoc, 6, 1060-83, doi:10.1038/nprot.2011.335.

EDGAR, R., DOMRACHEV, M. \& LASH, A. E. 2002. Gene Expression Omnibus: NCBI gene expression and hybridization array data repository. Nucleic Acids Res, 30, 207-10, doi:10.1093/nar/30.1.207.

FENG, H., AN, F., ZHANG, S., JI, Z., LING, H. Q. \& ZUO, J. 2006. Light-regulated, tissue-specific, and cell differentiation-specific expression of the Arabidopsis Fe(III)-chelate reductase gene AtFRO6. Plant Physiol, 140, 1345-54, doi:10.1104/pp.105.074138. 
FERNANDEZ-MILMANDA, G. L. \& BALLARE, C. L. 2021. Shade Avoidance: Expanding the Color and Hormone Palette. Trends Plant Sci, 26, 509-523, doi:10.1016/j.tplants.2020.12.006.

FIORUCCI, A. S. \& FANKHAUSER, C. 2017. Plant Strategies for Enhancing Access to Sunlight. Curr Biol, 27, R931-R940, doi:10.1016/j.cub.2017.05.085.

FIORUCCI, A. S., GALVAO, V. C., INCE, Y. C., BOCCACCINI, A., GOYAL, A., ALLENBACH PETROLATI, L., TREVISAN, M. \& FANKHAUSER, C. 2019. PHYTOCHROME INTERACTING FACTOR 7 is important for early responses to elevated temperature in Arabidopsis seedlings. New Phytol, 226, 50-58, doi:10.1111/nph.16316.

FUJIMORI, T., YAMASHINO, T., KATO, T. \& MIZUNO, T. 2004. Circadiancontrolled basic/helix-loop-helix factor, PIL6, implicated in light-signal transduction in Arabidopsis thaliana. Plant Cell Physiol, 45, 1078-86, doi:10.1093/pcp/pch124.

GAGNEBIN, Y., TONOLI, D., LESCUYER, P., PONTE, B., DE SEIGNEUX, S., MARTIN, P. Y., SCHAPPLER, J., BOCCARD, J. \& RUDAZ, S. 2017.

Metabolomic analysis of urine samples by UHPLC-QTOF-MS: Impact of normalization strategies. Anal Chim Acta, 955, 27-35, doi:10.1016/j.aca.2016.12.029.

GALVAO, V. C., FIORUCCI, A. S., TREVISAN, M., FRANCO-ZORILLA, J. M., GOYAL, A., SCHMID-SIEGERT, E., SOLANO, R. \& FANKHAUSER, C. 2019. PIF transcription factors link a neighbor threat cue to accelerated reproduction in Arabidopsis. Nat Commun, 10, 4005, doi:10.1038/s41467-01911882-7.

GE, S. X., JUNG, D. \& YAO, R. 2020. ShinyGO: a graphical gene-set enrichment tool for animals and plants. Bioinformatics, 36, 2628-2629, doi:10.1093/bioinformatics/btz931.

GENDREAU, E., TRAAS, J., DESNOS, T., GRANDJEAN, O., CABOCHE, M. \& HOFTE, H. 1997. Cellular basis of hypocotyl growth in Arabidopsis thaliana. Plant Physiol, 114, 295-305, doi:10.1104/pp.114.1.295.

GENDREL, A. V., LIPPMAN, Z., MARTIENSSEN, R. \& COLOT, V. 2005. Profiling histone modification patterns in plants using genomic tiling microarrays. Nat Methods, 2, 213-8, doi:10.1038/nmeth0305-213.

GOCZE, P. M. \& FREEMAN, D. A. 1994. Factors underlying the variability of lipid droplet fluorescence in MA-10 Leydig tumor cells. Cytometry, 17, 151-8, doi:10.1002/cyto.990170207.

GOTO-YAMADA, S., OIKAWA, K., BIZAN, J., SHIGENOBU, S., YAMAGUCHI, K., MANO, S., HAYASHI, M., UEDA, H., HARA-NISHIMURA, I., NISHIMURA, M. \& YAMADA, K. 2019. Sucrose Starvation Induces Microautophagy in Plant Root Cells. Front Plant Sci, 10, 1604, doi:10.3389/fpls.2019.01604.

GRAHAM, I. A. 2008. Seed storage oil mobilization. Annu Rev Plant Biol, 59, 115-42, doi:10.1146/annurev.arplant.59.032607.092938.

GRONNIER, J., LEGRAND, A., LOQUET, A., HABENSTEIN, B., GERMAIN, V. \& MONGRAND, S. 2019. Mechanisms governing subcompartmentalization of biological membranes. Curr Opin Plant Biol, 52, 114-123, doi:10.1016/j.pbi.2019.08.003. 
HASE, Y., FUJIOKA, S., YOSHIDA, S., SUN, G., UMEDA, M. \& TANAKA, A. 2005. Ectopic endoreduplication caused by sterol alteration results in serrated petals in Arabidopsis. $J$ Exp Bot, 56, 1263-8, doi:10.1093/jxb/eri122.

HE, J. X., FUJIOKA, S., LI, T. C., KANG, S. G., SETO, H., TAKATSUTO, S., YOSHIDA, S. \& JANG, J. C. 2003. Sterols regulate development and gene expression in Arabidopsis. Plant Physiol, 131, 1258-69, doi:10.1104/pp.014605.

HEPLER, P. K., ROUNDS, C. M. \& WINSHIP, L. J. 2013. Control of cell wall extensibility during pollen tube growth. Mol Plant, 6, 998-1017, doi: $10.1093 / \mathrm{mp} / \mathrm{sst} 103$.

HERSCH, M., LORRAIN, S., DE WIT, M., TREVISAN, M., LJUNG, K., BERGMANN, S. \& FANKHAUSER, C. 2014. Light intensity modulates the regulatory network of the shade avoidance response in Arabidopsis. Proc Natl Acad Sci U S A, 111, 6515-20, doi:10.1073/pnas.1320355111.

HOFIUS, D., SCHULTZ-LARSEN, T., JOENSEN, J., TSITSIGIANNIS, D. I., PETERSEN, N. H., MATTSSON, O., JORGENSEN, L. B., JONES, J. D., MUNDY, J. \& PETERSEN, M. 2009. Autophagic components contribute to hypersensitive cell death in Arabidopsis. Cell, 137, 773-83, doi:10.1016/j.cell.2009.02.036.

HORNITSCHEK, P., KOHNEN, M. V., LORRAIN, S., ROUGEMONT, J., LJUNG, K., LOPEZ-VIDRIERO, I., FRANCO-ZORRILLA, J. M., SOLANO, R., TREVISAN, M., PRADERVAND, S., XENARIOS, I. \& FANKHAUSER, C. 2012. Phytochrome interacting factors 4 and 5 control seedling growth in changing light conditions by directly controlling auxin signaling. Plant J, 71, 699711, doi:10.1111/j.1365-313X.2012.05033.x.

HU, S., YE, H., CUI, Y. \& JIANG, L. 2020. AtSec62 is critical for plant development and is involved in ER-phagy in Arabidopsis thaliana. J Integr Plant Biol, 62, 181200, doi:10.1111/jipb.12872.

IBANEZ, C., DELKER, C., MARTINEZ, C., BURSTENBINDER, K., JANITZA, P., LIPPMANN, R., LUDWIG, W., SUN, H., JAMES, G. V., KLECKER, M., GROSSJOHANN, A., SCHNEEBERGER, K., PRAT, S. \& QUINT, M. 2018. Brassinosteroids Dominate Hormonal Regulation of Plant Thermomorphogenesis via BZR1. Curr Biol, 28, 303-310 e3, doi:10.1016/j.cub.2017.11.077.

INCE, Y. C. \& GALVAO, V. C. 2021. Analysis of Shade-Induced Hypocotyl Elongation in Arabidopsis. Methods Mol Biol, 2297, 21-31, doi:10.1007/978-1-0716-137023.

IZUMI, M., HIDEMA, J., MAKINO, A. \& ISHIDA, H. 2013. Autophagy contributes to nighttime energy availability for growth in Arabidopsis. Plant Physiol, 161, 168293, doi:10.1104/pp.113.215632.

KELLER, M. M., JAILLAIS, Y., PEDMALE, U. V., MORENO, J. E., CHORY, J. \& BALLARE, C. L. 2011. Cryptochrome 1 and phytochrome B control shadeavoidance responses in Arabidopsis via partially independent hormonal cascades. Plant J, 67, 195-207, doi:10.1111/j.1365-313X.2011.04598.x.

KEUSKAMP, D. H., POLLMANN, S., VOESENEK, L. A., PEETERS, A. J. \& PIERIK, R. 2010. Auxin transport through PIN-FORMED 3 (PIN3) controls shade avoidance and fitness during competition. Proc Natl Acad Sci U S A, 107, 227404, doi:10.1073/pnas.1013457108. 
KEUSKAMP, D. H., SASIDHARAN, R., VOS, I., PEETERS, A. J., VOESENEK, L. A. \& PIERIK, R. 2011. Blue-light-mediated shade avoidance requires combined auxin and brassinosteroid action in Arabidopsis seedlings. Plant J, 67, 208-17, doi:10.1111/j.1365-313X.2011.04597.x.

KOHNEN, M. V., SCHMID-SIEGERT, E., TREVISAN, M., PETROLATI, L. A., SENECHAL, F., MULLER-MOULE, P., MALOOF, J., XENARIOS, I. \& FANKHAUSER, C. 2016. Neighbor Detection Induces Organ-Specific Transcriptomes, Revealing Patterns Underlying Hypocotyl-Specific Growth. Plant Cell, 28, 2889-2904, doi:10.1105/tpc.16.00463.

KOZUKA, T., KOBAYASHI, J., HORIGUCHI, G., DEMURA, T., SAKAKIBARA, H., TSUKAYA, H. \& NAGATANI, A. 2010. Involvement of auxin and brassinosteroid in the regulation of petiole elongation under the shade. Plant Physiol, 153, 1608-18, doi:10.1104/pp.110.156802.

KOZUKA, T., SAWADA, Y., IMAI, H., KANAI, M., HIRAI, M. Y., MANO, S., UEMURA, M., NISHIMURA, M., KUSABA, M. \& NAGATANI, A. 2020. Regulation of Sugar and Storage Oil Metabolism by Phytochrome during Deetiolation. Plant Physiol, 182, 1114-1129, doi:10.1104/pp.19.00535.

LEGRIS, M., INCE, Y. C. \& FANKHAUSER, C. 2019. Molecular mechanisms underlying phytochrome-controlled morphogenesis in plants. Nat Commun, 10, 5219, doi:10.1038/s41467-019-13045-0.

LEIVAR, P., MONTE, E., AL-SADY, B., CARLE, C., STORER, A., ALONSO, J. M., ECKER, J. R. \& QUAIL, P. H. 2008. The Arabidopsis phytochrome-interacting factor PIF7, together with PIF3 and PIF4, regulates responses to prolonged red light by modulating phyB levels. Plant Cell, 20, 337-52, doi:10.1105/tpc.107.052142.

LI, F. \& VIERSTRA, R. D. 2012. Autophagy: a multifaceted intracellular system for bulk and selective recycling. Trends Plant Sci, 17, 526-37, doi:10.1016/j.tplants.2012.05.006.

LI, L., LJUNG, K., BRETON, G., SCHMITZ, R. J., PRUNEDA-PAZ, J., COWINGZITRON, C., COLE, B. J., IVANS, L. J., PEDMALE, U. V., JUNG, H. S., ECKER, J. R., KAY, S. A. \& CHORY, J. 2012. Linking photoreceptor excitation to changes in plant architecture. Genes Dev, 26, 785-90, doi:10.1101/gad.187849.112.

LIU, J. \& VAN IERSEL, M. W. 2021. Photosynthetic Physiology of Blue, Green, and Red Light: Light Intensity Effects and Underlying Mechanisms. Front Plant Sci, 12, 619987, doi:10.3389/fpls.2021.619987.

LORRAIN, S., ALLEN, T., DUEK, P. D., WHITELAM, G. C. \& FANKHAUSER, C. 2008. Phytochrome-mediated inhibition of shade avoidance involves degradation of growth-promoting bHLH transcription factors. Plant J, 53, 312-23, doi:10.1111/j.1365-313X.2007.03341.X.

MA, D., LI, X., GUO, Y., CHU, J., FANG, S., YAN, C., NOEL, J. P. \& LIU, H. 2016. Cryptochrome 1 interacts with PIF4 to regulate high temperature-mediated hypocotyl elongation in response to blue light. Proc Natl Acad Sci US A, 113, 224-9, doi:10.1073/pnas.1511437113.

MAMODE CASSIM, A., GOUGUET, P., GRONNIER, J., LAURENT, N., GERMAIN, V., GRISON, M., BOUTTE, Y., GERBEAU-PISSOT, P., SIMON-PLAS, F. \& 
MONGRAND, S. 2019. Plant lipids: Key players of plasma membrane organization and function. Prog Lipid Res, 73, 1-27, doi:10.1016/j.plipres.2018.11.002.

MARTIN, M. 2011. Cutadapt removes adapter sequences from high-throughput sequencing reads. EMBnet.journal, 17, doi:10.14806/ej.17.1.200.

MCCREE, K. J. 1971. The action spectrum, absorptance and quantum yield of photosynthesis in crop plants. Agricultural Meteorology, 9, 191-216, doi:10.1016/0002-1571(71)90022-7.

MORAES, T. A., MENGIN, V., ANNUNZIATA, M. G., ENCKE, B., KROHN, N., HOHNE, M. \& STITT, M. 2019. Response of the Circadian Clock and Diel Starch Turnover to One Day of Low Light or Low CO2. Plant Physiol, 179, 1457-1478, doi:10.1104/pp.18.01418.

MUller-MOUlE, P., NOZUE, K., PYTLAK, M. L., PALMER, C. M., COVINGTON, M. F., WALLACE, A. D., HARMER, S. L. \& MALOOF, J. N. 2016. YUCCA auxin biosynthetic genes are required for Arabidopsis shade avoidance. PeerJ, 4, e2574, doi:10.7717/peerj.2574.

NITO, K., KAJIYAMA, T., UNTEN-KOBAYASHI, J., FUJI, A., MOCHIZUKI, N., KAMBARA, H. \& NAGATANI, A. 2015. Spatial Regulation of the Gene Expression Response to Shade in Arabidopsis Seedlings. Plant Cell Physiol, 56, 1306-19, doi:10.1093/pcp/pcv057.

NOZUE, K., TAT, A. V., KUMAR DEVISETTY, U., ROBINSON, M., MUMBACH, M. R., ICHIHASHI, Y., LEKKALA, S. \& MALOOF, J. N. 2015. Shade avoidance components and pathways in adult plants revealed by phenotypic profiling. PLoS Genet, 11, e1004953, doi:10.1371/journal.pgen.1004953.

OH, E., ZHU, J. Y., BAI, M. Y., ARENHART, R. A., SUN, Y. \& WANG, Z. Y. 2014. Cell elongation is regulated through a central circuit of interacting transcription factors in the Arabidopsis hypocotyl. Elife, 3, doi:10.7554/eLife.03031.

OH, E., ZHU, J. Y. \& WANG, Z. Y. 2012. Interaction between BZR1 and PIF4 integrates brassinosteroid and environmental responses. Nat Cell Biol, 14, 802-9, doi:10.1038/ncb2545.

PEDMALE, U. V., HUANG, S. C., ZANDER, M., COLE, B. J., HETZEL, J., LJUNG, K., REIS, P. A. B., SRIDEVI, P., NITO, K., NERY, J. R., ECKER, J. R. \& CHORY, J. 2016. Cryptochromes Interact Directly with PIFs to Control Plant Growth in Limiting Blue Light. Cell, 164, 233-245, doi:10.1016/j.cell.2015.12.018.

PIERIK, R., DJAKOVIC-PETROVIC, T., KEUSKAMP, D. H., DE WIT, M. \& VOESENEK, L. A. 2009. Auxin and ethylene regulate elongation responses to neighbor proximity signals independent of gibberellin and della proteins in Arabidopsis. Plant Physiol, 149, 1701-12, doi:10.1104/pp.108.133496.

PROCKO, C., BURKO, Y., JAILLAIS, Y., LJUNG, K., LONG, J. A. \& CHORY, J. 2016. The epidermis coordinates auxin-induced stem growth in response to shade. Genes Dev, 30, 1529-41, doi:10.1101/gad.283234.116.

PROCKO, C., CRENSHAW, C. M., LJUNG, K., NOEL, J. P. \& CHORY, J. 2014. Cotyledon-Generated Auxin Is Required for Shade-Induced Hypocotyl Growth in Brassica rapa. Plant Physiol, 165, 1285-1301, doi:10.1104/pp.114.241844. 
PUCCIARIELLO, O., LEGRIS, M., COSTIGLIOLO ROJAS, C., IGLESIAS, M. J., HERNANDO, C. E., DEZAR, C., VAZQUEZ, M., YANOVSKY, M. J., FINLAYSON, S. A., PRAT, S. \& CASAL, J. J. 2018. Rewiring of auxin signaling under persistent shade. Proc Natl Acad Sci U S A, 115, 5612-5617, doi:10.1073/pnas.1721110115.

QIU, Y. 2020. Regulation of PIF4-mediated thermosensory growth. Plant Sci, 297, 110541, doi:10.1016/j.plantsci.2020.110541.

RITCHIE, M. E., PHIPSON, B., WU, D., HU, Y., LAW, C. W., SHI, W. \& SMYTH, G. K. 2015. limma powers differential expression analyses for RNA-sequencing and microarray studies. Nucleic Acids Res, 43, e47, doi:10.1093/nar/gkv007.

ROBINSON, M. D., MCCARTHY, D. J. \& SMYTH, G. K. 2010. edgeR: a Bioconductor package for differential expression analysis of digital gene expression data. Bioinformatics, 26, 139-40, doi:10.1093/bioinformatics/btp616.

SMITH, A. M. \& STITT, M. 2007. Coordination of carbon supply and plant growth. Plant Cell Environ, 30, 1126-49, doi:10.1111/j.1365-3040.2007.01708.x.

STEER, M. W. \& STEER, J. M. 1989. Pollen tube tip growth. New Phytologist, 111, 323-358, doi:10.1111/j.1469-8137.1989.tb00697.x.

STEPHANI, M., PICCHIANTI, L., GAJIC, A., BEVERIDGE, R., SKARWAN, E., SANCHEZ DE MEDINA HERNANDEZ, V., MOHSENI, A., CLAVEL, M., ZENG, Y., NAUMANN, C., MATUSZKIEWICZ, M., TURCO, E., LOEFKE, C., LI, B., DURNBERGER, G., SCHUTZBIER, M., CHEN, H. T., ABDRAKHMANOV, A., SAVOVA, A., CHIA, K. S., DJAMEI, A., SCHAFFNER, I., ABEL, S., JIANG, L., MECHTLER, K., IKEDA, F., MARTENS, S., CLAUSEN, T. \& DAGDAS, Y. 2020. A cross-kingdom conserved ER-phagy receptor maintains endoplasmic reticulum homeostasis during stress. Elife, 9, doi:10.7554/eLife.58396.

SUN, N., WANG, J., GAO, Z., DONG, J., HE, H., TERZAGHI, W., WEI, N., DENG, X. W. \& CHEN, H. 2016. Arabidopsis SAURs are critical for differential light regulation of the development of various organs. Proc Natl Acad Sci US A, 113, 6071-6, doi:10.1073/pnas.1604782113.

TAO, Y., FERRER, J. L., LJUNG, K., POJER, F., HONG, F., LONG, J. A., LI, L., MORENO, J. E., BOWMAN, M. E., IVANS, L. J., CHENG, Y., LIM, J., ZHAO, Y., BALLARE, C. L., SANDBERG, G., NOEL, J. P. \& CHORY, J. 2008. Rapid synthesis of auxin via a new tryptophan-dependent pathway is required for shade avoidance in plants. Cell, 133, 164-76, doi:10.1016/j.cell.2008.01.049.

THOMPSON, A. R., DOELLING, J. H., SUTTANGKAKUL, A. \& VIERSTRA, R. D. 2005. Autophagic Nutrient Recycling in Arabidopsis Directed by the ATG8 and ATG12 Conjugation Pathways. Plant Physiology, 138, 2097-2110, doi:10.1104/pp.105.060673.

TSUGAWA, H., CAJKA, T., KIND, T., MA, Y., HIGGINS, B., IKEDA, K., KANAZAWA, M., VANDERGHEYNST, J., FIEHN, O. \& ARITA, M. 2015. MS-DIAL: data-independent MS/MS deconvolution for comprehensive metabolome analysis. Nat Methods, 12, 523-6, doi:10.1038/nmeth.3393.

VALITOVA, J. N., SULKARNAYEVA, A. G. \& MINIBAYEVA, F. V. 2016. Plant Sterols: Diversity, Biosynthesis, and Physiological Functions. Biochemistry (Mosc), 81, 819-34, doi:10.1134/S0006297916080046. 
VAN LEENE, J., HAN, C., GADEYNE, A., EECKHOUT, D., MATTHIJS, C., CANNOOT, B., DE WINNE, N., PERSIAU, G., VAN DE SLIJKE, E., VAN DE COTTE, B., STES, E., VAN BEL, M., STORME, V., IMPENS, F., GEVAERT, K., VANDEPOELE, K., DE SMET, I. \& DE JAEGER, G. 2019. Capturing the phosphorylation and protein interaction landscape of the plant TOR kinase. Nat Plants, 5, 316-327, doi:10.1038/s41477-019-0378-z.

VERBANCIC, J., LUNN, J. E., STITT, M. \& PERSSON, S. 2018. Carbon Supply and the Regulation of Cell Wall Synthesis. Mol Plant, 11, 75-94, doi:10.1016/j.molp.2017.10.004.

WANG, L., WANG, S. \& LI, W. 2012. RSeQC: quality control of RNA-seq experiments. Bioinformatics, 28, 2184-5, doi:10.1093/bioinformatics/bts635.

WANG, P., MUGUME, Y. \& BASSHAM, D. C. 2018. New advances in autophagy in plants: Regulation, selectivity and function. Semin Cell Dev Biol, 80, 113-122, doi:10.1016/j.semcdb.2017.07.018.

WANG, X., GAO, X., LIU, Y., FAN, S. \& MA, Q. 2020. Progress of Research on the Regulatory Pathway of the Plant Shade-Avoidance Syndrome. Front Plant Sci, 11, 439, doi:10.3389/fpls.2020.00439.

WINGETT, S. W. \& ANDREWS, S. 2018. FastQ Screen: A tool for multi-genome mapping and quality control. F1000Res, 7, 1338, doi:10.12688/f1000research.15931.2.

YOSHIMOTO, K., HANAOKA, H., SATO, S., KATO, T., TABATA, S., NODA, T. \& OHSUMI, Y. 2004. Processing of ATG8s, ubiquitin-like proteins, and their deconjugation by ATG4s are essential for plant autophagy. Plant Cell, 16, 296783, doi:10.1105/tpc.104.025395.

YU, M., CUI, Y., ZHANG, X., LI, R. \& LIN, J. 2020. Organization and dynamics of functional plant membrane microdomains. Cell Mol Life Sci, 77, 275-287, doi:10.1007/s00018-019-03270-7.

ZHANG, B., HOLMLUND, M., LORRAIN, S., NORBERG, M., BAKO, L., FANKHAUSER, C. \& NILSSON, O. 2017. BLADE-ON-PETIOLE proteins act in an E3 ubiquitin ligase complex to regulate PHYTOCHROME INTERACTING FACTOR 4 abundance. Elife, 6, doi:10.7554/eLife.26759.

ZHENG, Z., GUO, Y., NOVAK, O., CHEN, W., LJUNG, K., NOEL, J. P. \& CHORY, J. 2016. Local auxin metabolism regulates environment-induced hypocotyl elongation. Nat Plants, 2, 16025, doi:10.1038/nplants.2016.25. 